\title{
Results of Monte Carlo Calculations of Neutron Spectra and Doses Outside the BDMS Shielding
}

R.P. Radev, J.M. Hall

October 16, 2000

U.S. Department of Energy

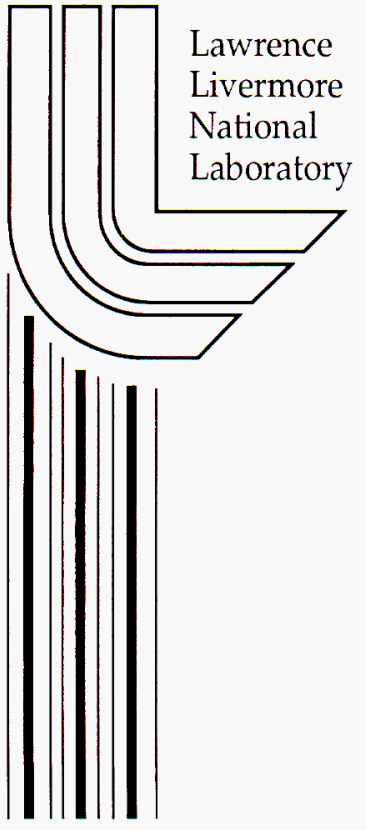




\section{DISCLAIMER}

This document was prepared as an account of work sponsored by an agency of the United States Government. Neither the United States Government nor the University of California nor any of their employees, makes any warranty, express or implied, or assumes any legal liability or responsibility for the accuracy, completeness, or usefulness of any information, apparatus, product, or process disclosed, or represents that its use would not infringe privately owned rights. Reference herein to any specific commercial product, process, or service by trade name, trademark, manufacturer, or otherwise, does not necessarily constitute or imply its endorsement, recommendation, or favoring by the United States Government or the University of California. The views and opinions of authors expressed herein do not necessarily state or reflect those of the United States Government or the University of California, and shall not be used for advertising or product endorsement purposes.

This work was performed under the auspices of the U.S. Department of Energy by the University of California, Lawrence Livermore National Laboratory under Contract No. W-7405-Eng-48.

This report has been reproduced directly from the best available copy.

Available electronically at http://www.doe.gov/bridge

Available for a processing fee to U.S. Department of Energy

and its contractors in paper from

U.S. Department of Energy

Office of Scientific and Technical Information

P.O. Box 62

Oak Ridge, TN 37831-0062

Telephone: (865) 576-8401

Facsimile: (865) 576-5728

E-mail: reports@adonis.osti.gov

Available for the sale to the public from

U.S. Department of Commerce

National Technical Information Service

5285 Port Royal Road

Springfield, VA 22161

Telephone: (800) 553-6847

Facsimile: (703) 605-6900

E-mail: orders@ntis.fedworld.gov

Online ordering: http://www.ntis.gov/ordering.htm

OR

Lawrence Livermore National Laboratory

Technical Information Department's Digital Library

http://www.llnl.gov/tid/Library.html 


\title{
RESULTS OF MONTE CARLO CALCULATIONS OF NEUTRON SPECTRA AND DOSES OUTSIDE THE BDMS SHIELDING
}

\author{
Radoslav P. Radev and James M. Hall \\ Lawrence Livermore National Laboratory
}

\section{Summary}

A set of Monte Carlo calculations of the neutron dose rates and neutron spectra outside BDMS shielding were performed with U.S. and Russian neutron fluence-to-dose conversion coefficients. The purpose of these calculations was to facilitate the proper interpretation of the dose rate measurements from rem meters outside the BDMS shielding. An accurate determination of the dose rate is of particular interest so that dose rate can be compared with the applicable regulatory limit. The calculations show that the neutrons outside the BDMS shielding are significantly reduced in energy, i.e. the spectrum is shifted (moderated) towards the lower energies and contains significantly larger amount of neutrons in the energy range below $100 \mathrm{keV}$. The result of these calculations indicates that the dose measurement for the BDMS neutrons is overestimated from $25 \%$ to $55 \%$ depending on the location around BDMS when using either Russian or U.S. dose conversion coefficients. For an accurate neutron dose determination the application of an appropriate correcting factor to the neutron dose measurement is necessary.

\section{Background}

The radiation dose (dose equivalent) from neutron radiation depends on several factors, most notably their energy and their relative biological effectiveness (quality factor, Q). For any given energy, the dose from neutrons $\mathbf{D}_{\mathbf{e}}$ is proportional to the number of neutrons $\mathbf{N}$ and the quality factor $\mathbf{Q}$.

$$
\mathbf{D}_{\mathbf{e}} \sim \mathbf{N} \cdot \mathbf{Q}
$$

The quality factor $Q$ is strongly dependent on the neutron energy. Therefore, the same amount of neutron radiation will deliver different amount of dose depending on its energy and consequently will have a different health effect to the human body. The U.S. and Russian safety regulations provide tables with $Q$ values or the associated neutron fluenceto-dose conversion coefficients for different energy intervals. In Table 1 are presented the current quality factors used in the U.S.A. and Russia.

For example, if two individuals are exposed to the same amount of monoenergetic neutrons but with different energies $E_{1}$ and $E_{2}$ and the respective quality factor for energy $E_{2}$ is twice as large as for $E_{1}$ (i.e. $Q_{2}=2$. $Q_{1}$ ), then the radiation dose $D_{2}$ from neutrons with energy $E_{2}$ will be two times greater then the dose $D_{1}$ from neutrons with energy $E_{1}$ (i.e. $\mathrm{D}_{2}=2 . \mathrm{D}_{1}$ ). If we have non-monoenergetic neutrons with some spectral distribution, the dose from these neutrons is determined by integrating the product of the number of the neutrons in each energy interval and the corresponding quality factor for that energy.

$$
\mathbf{D} \sim \int \mathbf{N}(\mathbf{e}) \cdot \mathbf{Q}(\mathbf{e}) \cdot \mathrm{de}
$$


Therefore, in order to determine accurately the radiation dose from neutrons with a wide spectrum, the knowledge of the neutron spectrum distribution $\mathbf{N}(\mathbf{e})$ is essential. There is no consensus at this time on the appropriate choice for the value of the quality factor for neutrons. A variety of factors have been recommended by national, international and regulatory bodies. These factors vary due to differences in the choice of phantom geometry, depth at which the dose equivalent is to be determined, and the assessment of the relative biological risk of neutrons to photons. The latest American National Standard Institute (ANSI) standard N13.52 "Personnel Neutron Dosimeters" [1] does not adopt or preclude the use of any of the conventions listed above. More information and discussion is provided in Appendix 1.

\section{Dose estimation from BDMS moderated neutrons}

The Blend Down Monitoring System (BDMS) is designed to continuously monitor the ${ }^{235} \mathrm{U}$ enrichment and mass flow rates in processing pipes at uranium facilities [2-11]. The BDMS mass flow monitor incorporates four Cf neutron sources ( $\sim 3 \mathrm{~g}$ each) surrounded by a polyethylene shielding block. The BDMS shielding reduces the energy (moderates) of the neutrons from the $\mathrm{Cf}$ sources. A neutron-absorbing shutter moves back and forth in front of the Cf sources thus changing their energy and intensity. It is expected that the dose from neutrons with moderated spectrum would be less than the dose from a bare $\mathrm{Cf}$ source because the quality factor for the average neutron energy of a bare Cf source $\left(\mathrm{E}_{\mathrm{av}}\right.$ $=2.3 \mathrm{MeV}$ ) is 4 to 5 times higher then the quality factor for neutron energies below 1 keV (see Fig. 1 and Table 1). Therefore, for accurate determination of the dose from the BDMS moderated neutrons it is necessary to know how many neutrons have been moderated and how much their energy was reduced. In other words we need to know the precise spectrum of the BDMS neutrons in order to accurately determine the dose from BDMS neutrons. In variety of applications it has been reported that the use of a 10 " polyethylene sphere dose meter (a.k.a. rem ball) leads to a maximum dose overestimation of $65 \%$ [3].

One can measure or calculate the BDMS neutron spectrum but the measurement of the neutron spectrum is rather complex and time-consuming task. There is no single detector or techniques that can be applied for the entire energy spectrum, which necessitates the calibration of several types of detectors with suitable sources in various overlapping energy intervals. Few laboratories have the complete set of neutron detectors, the neutron spectra unfolding methodologies, and calibration sources to perform an accurate measurement of a wide neutron spectrum. On the other hand, the calculation of the spectrum even in relatively complex geometries can be done accurately, takes less time and effort, and overall is a safer and more cost effective approach.

\section{Calculation of the BDMS moderated neutron spectra}

LLNL ran series of Monte Carlo calculations to estimate the neutron and photon spectra and the associated doses outside the BDMS shielding. As in the earlier calculations [4], the COG code [22] (LLNL's equivalent to MNCP) was used with neutron and gamma data derived from ENDL and EPDL libraries and a ${ }^{252} \mathrm{Cf}$ source model based on the IAEA standard of ${ }^{252} \mathrm{Cf}$ [5]. The detector response function was assumed to be independent of the neutron energy. The neutron spectra were determined at different locations on the surface and at 1 meter away from the BDMS shielding (Fig. 2). 
The neutron spectrum and dose calculations were run for two situations: source shutter assembly in open position and shutter assembly in closed position. Graphs of the neutron spectra at different locations on and around the BDMS shielding are provided in Fig. 3-8 for the open shutter position and in Fig. 9-14 for the closed shutter position. On these graphs the left-hand side ordinate scale applies to the spectral distribution of neutrons arriving at a particular location (e.g. 401,..406). The spectra are normalized to one neutron (arriving at a particular location) per one $\mathrm{cm}^{2}$ and per unit of energy (MeV). The neutron spectra for open and close shutter positions do not differ for the entire spectrum with exception of the region below $0.4 \mathrm{eV}$. As expected, the neutron-absorbing shutter reduces the thermal neutron contribution from two to five times at different dose measurement locations.

The unmoderated $\mathrm{Cf}$ neutron spectrum was modeled after the IAEA reference $\mathrm{Cf}$ source [5] at one meter away from the source. Graph of the calculated neutron spectrum in air one meter away from a bare ${ }^{252} \mathrm{Cf}$ source, normalized to one neutron per $1 \mathrm{~cm}^{2}$ per unit energy, is provided in Fig. 15.

It is apparent from the graphs that the BDMS moderated neutron spectra have lower contribution of high energy neutrons in the range $0.1-5 \mathrm{MeV}$ and significantly higher contribution of low energy neutrons below $0.1 \mathrm{MeV}$ than the neutron spectra from a bare ${ }^{252} \mathrm{Cf}$ source in air. The increase of the BDMS moderated neutrons in the energy region below $1 \mathrm{keV}$ is more then four orders of magnitude higher compared with the neutron spectral distribution of a bare $\mathrm{Cf}$ source. Figures 16-27 provide a visual representation of the neutron spectra moderation, i.e. shift towards the lower energies, as a result of the BDMS shielding. Figures 16-21 present the cumulative integrals of the normalized BDMS neutron spectra per $1 \mathrm{~cm}^{2}$ for open shutter position and Figures 22-27 present the same spectra for the closed shutter position.

\section{Calculation and evaluation of the neutron dose rates outside the BDMS shielding}

The neutron dose rates were estimated using the calculated neutron spectra and the published U.S. and Russian quality factors tables and the associated neutron fluence-todose conversion coefficients. A detector response function independent of the energy was used. The data for the quality factors were derived from the American National Standards Institute (ANSI) standards [6] and [7] and NRB-99 (Russian regulatory document) [8]. The NRB-99 document provides tables of the neutron fluence-to-dose conversion coefficients for two types of neutron radiation (see Table 2): isotropic neutron field where neutrons strike the body uniformly from every direction (IRF column in Table 2) and a parallel neutron field, where neutrons strikes the body in parallel beam in front-to-back direction (F-B column in Table 2). Additional information on the controversy surrounding the best choice for the quality factor and the neutron fluence-todose conversion coefficients is provided in Appendix 1.

Graphs of the energy distribution of the neutron dose rates at different locations on and around BDMS are plotted on the same charts together with the neutron spectra for open (Fig. 3-8) and closed (Fig 9-14) shutter positions. The dose ordinate scale is on the right hand-side of the chart and it is given in units of rem per one neutron (arriving at the particular location) per $1 \mathrm{~cm}^{2}$. The dose distributions are presented on each chart for the 
two U.S. and two Russian neutron fluence-to-dose conversion factors. Table 2 provides the latest published Russian neutron fluence-to-dose conversion coefficients [8].

The neutron dose rates at any location are determined by the contribution of the neutrons with all the energies in the spectrum. Therefore, in order to obtain the total neutron dose rate an individual would be exposed to from neutrons with a wide spectrum, it is necessary to integrate the partial neutron dose rates over the entire spectrum. A summary of the integrated neutron dose rates at 1 meter away from both a bare $\mathrm{Cf}$ source and a $\mathrm{Cf}$ source moderated by the BDMS shielding neutrons at different locations on and around the BDMS shielding is provided in Table 3. The dose rates are normalized to one neutron arriving at the particular location per one second.

The integrated neutron dose rates vary approximately $10 \%$ for open and closed source shutter positions. The actual difference depends on the particular location where the dose rate is evaluated since the source-detector geometry and the shutter position are not symmetrical for all locations where the dose rates and spectra are calculated. As can be seen from the summary in Table 3, the integral dose rates calculated with both U.S. and Russian dose conversion coefficients are $25 \%$ to $55 \%$ smaller than the dose rates from a bare $\mathrm{Cf}$ source. This difference depends on the particular location around the BDMS. For location 406 (one meter away from the BDMS shielding) the overestimation of the dose rate from BDMS moderated neutrons over a dose rate from a bare $\mathrm{Cf}$ source is from $25 \%$ to $40 \%$ depending on the particular fluence-to-dose conversion coefficients used. Therefore, we can conservatively assume that for locations at one meter away from the BDMS shielding the overestimation is at least $25 \%$ over a measurement made with a dose meter calibrated with bare unmoderated $\mathrm{Cf}$ source.

\section{Calculation of the total dose rates outside the BDMS shielding}

The neutron radiation is always accompanied by gamma radiation from the source and/or from activation or induced neutron reactions. Therefore, the total dose rate around BDMS is the sum of the neutron and gamma dose rates. The dose rates were calculated from a neutron source consisting of four $4 \mu \mathrm{g}{ }^{252} \mathrm{Cf}$ sources located in the BDMS as described in [2] and using a detector response function independent of the energy. The calculated neutron, gamma and total dose rates are presented in Table 4 in units of $\mathrm{mrem} / \mathrm{hr}$.

The calculated total dose rates at 1 meter from the BDMS (locations 405 and 406) are below the Russian regulatory limit of $0.3 \mathrm{mrem} / \mathrm{hr}$ [8]:

\begin{tabular}{|c|c|c|}
\hline Location & $\frac{\frac{\text { Largest calculated }}{\text { dose rate }}}{(\mathrm{mrem} / \mathrm{hr})}$ & $\frac{\frac{\text { Russian regulatory }}{\text { dose rate limit }}}{\text { (mrem } / \mathrm{hr})}$ \\
\hline 405 & 0.24 & 0.3 \\
\hline 406 & 0.15 & 0.3 \\
\hline
\end{tabular}

The calculated total dose rates at the BDMS surface are below the Russian regulatory limit of $10 \mathrm{mrem} / \mathrm{hr}$ [8] with the exception of the calculations using the 1977 fluence-todose conversion coefficients [6] for surface locations on the pipe axis. At the time of the 
source installation an additional shielding was added to the BDMS at UEIE which was not accounted for in the present calculations. The statistical accuracy of the calculations using the COG code is better then $1 \%[22,23]$. The agreement between COG calculations and the measurement is evaluated to be 5-10\% [23].

\section{Conclusion}

The Monte Carlo calculations provided an accurate estimate of the neutron spectra moderation outside the BDMS shielding compared with an unmoderated Cf source spectrum. The calculation of the dose rates with both U.S. and Russian published fluence-to-dose conversion coefficients indicates that the neutron dose rates in various locations outside the BDMS are overestimated by $25 \%$ to $55 \%$ compared with the neutron dose rate from a bare unmoderated $\mathrm{Cf}$ source. The results of the calculation support the published data that the doses from neutrons with moderated Cf spectrum will be overestimated when measured with a dose rate meter (e.g. rem ball) calibrated with a unmoderated (bare) $\mathrm{Cf}$ source. In variety of applications the reported average dose overestimation is up to $65 \%$ with the precise amount being dependent on the particular application [3]. Conservatively we can assume that the neutron dose rate overestimation is $25 \%$, in other words, the actual neutron dose rate is at least $25 \%$ less than the dose rate directly determined from the detector readings. The calculations also showed that the total doses around BDMS are below the applicable Russian radiation safety regulatory limits.

\section{References}

1. ANSI 13.52 - 1999 "Personnel Neutron Dosimeters", American National Standard Institute, Inc. 1999.

2. José March-Leuba, J. K. Mattingly, J. A. Mullens, T. E. Valentine, J. T. Mihalczo, R. B. Perez. -"Methodology for Interpretation of Fissile Mass Flow Measurements" - 38th Annual Meeting of the Institute of Nuclear Materials Management, Phoenix, Arizona, July 20, 1997.

3. J. T. Mihalczo, José March-Leuba, T. E. Valentine, R. A. Abston, J. K. Mattingly, T. Uckan, J. A. McEvers, - "UF6 Fissile Mass Flow Simulation at the Oak Ridge National Laboratory" - 38th Annual Meeting of the Institute of Nuclear Materials Management, Phoenix, Arizona, July 20, 1997.

4. J. K. Munro, T. E. Valentine, R. B. Perez, J. K. Mattingly, José March-Leuba, J. T. Mihalczo. - "Fission Product Range Effects of HEU Fissile Mass Monitoring for HEU Blenddown" - 38th Annual Meeting of the Institute of Nuclear Materials Management, Phoenix, Arizona, July 20, 1997.

5. M. J. Paulus, T.Uckan, R. Lenarduzzi, J. March-Leuba, K. Catleberry, J. K. Mattingly, J. T. Mihalczo, J. A. Mullens, T. E. Valentine, J. A. McEvers. "Detector System for Monitoring Fissile Mass Flow in Liquids and Gases"

6. Jim McEvers, James Sumner, Richard Jones, Regina Ferrell, Carl Martin, Taner Uckan, José March-Leuba. - "Hardware Implementation of the ORNL Fissile Mass 
Flow Monitor" - 39th Annual Meeting of the Institute of Nuclear Materials Management, Naples, Florida, July 1998.

7. José March-Leuba, Taner Uckan, James Sumner, John Mattingly, John Mihalczo. "Calibration Measurements of the ORNL Fissile Mass Flow Monitor" - 39th Annual Meeting of the Institute of Nuclear Materials Management, Naples, Florida, July 1998.

8. J. Marchleuba, T. Uckan, J. Sumner, R. Vines, D. Powel, E. Mastal. -

"Commissioning Measurements and Experience Obtained from the Installation of a Fissile Mass Flow Monitor in the Ural Electrochemical Integrated Plant (UEIP) in Novouralsk" - 40th Annual Meeting of the Institute of Nuclear Materials Management, Phoenix, Arizona, July 1999.

9. Taner Uckan, Jose MarchLeuba, Jim Sumner, Bob Vines, Edward Mastal, and Danny Powell. - "Fissile Mass Flow Monitor Implementation for Transparency in HEU Blenddown at the Ural Electrochemical Integrated Plant (UEIP) in Novouralsk" - 40th Annual Meeting of the Institute of Nuclear Materials Management, Phoenix, Arizona, July 1999.

10. Donald A. Close, William S. Johnson, P. L. Kerr, Calvin E. Moss, Edward F. Mastal, Janie B. Benton, Joseph W. Glaser, Jose A. MarchLeuba, Danny H. Powell, James N. Sumner, Tanner Uckan, Robert A. Vines, Aleksandr V. Saprygin. "Installation and Operation of the BlendDown Monitoring System at the Ural Electrochemical Integrated Plant" - 40th Annual Meeting of the Institute of Nuclear Materials Management, Phoenix, Arizona, July 1999.

11. Jose A. MarchLeuba, Danny H. Powell, James N. Sumner, Tanner Uckan, Robert A. Vines, Donald L. Close, William S. Johnson, P. L. Kerr, Calvin E. Moss, P.D. Wright, Edward F. Mastal, Janie B. Benton. - "The BlendDown Monitoring System Demonstration at the Paducah Gaseous Diffusion Plant" - 40th Annual Meeting of the Institute of Nuclear Materials Management, Phoenix, Arizona, July 1999.

12. G. Knoll. - "Radiation Detection and Measurement", John Wiley and Sons, 1989.

D. Hankins. - Los Alamos report LA-2717 (1962)

D. Hankins, R. Pederson. - Los Alamos report LAMS-2977 (1964)

13. J. Hall. - "Shielding Calculations for UF 6 Enrichment and Flow Monitor" - LLNL interdepartmental memorandum to J. McEvers, May 28, 1997.

14. J. Hall, H. Rossi. - "Californium-252 in Teaching and Research" - IAEA Technical report series No. 159, 1974.

15. ANSU/ANS- 6.1.1 - 1977 edition. "Neutron and Gamma-Ray Flux-to-Dose Rate Factors", 1977.

16. ANSI-ANS - 6.1.1 - 1991 revision. "Neutron and Gamma-Ray Flux-to-Dose Rate Factors", 1991. 
17. Radiation Safety Norms (NRB-99) - Russian Radiation Safety Codes, Minzdrav of Russia Publishing House, 1999.

18. R. Griffith et al. - "Recent Developments in Personnel Neutron Dosimeters, A Review". Health Phys. Vol. 36 (1979) p. 235

19. H. Ing, E. Piesch. - "Status of Neutron Dosimetry". Radiation Protection Dosimetry, Vol. 10 (1985) p. 515

20. J. Gibson. - "Individual Neutron Dosimetry". Radiation Protection Dosimetry, Vol. 23 (1988) p. 109

21. C. Eisenhauer, R. Schwartz. - "Analysis of Measurements with Personnel Dosimeters and Portable Instruments for Determining Neutron Dose Equivalent at Nuclear Power Plants". NUREG/CR 3400

22. G. Burger, H. Ebert. - "Proceedings of the Fourth Symposium on Neutron Dosimetry” CEC EUR 7448 EN, Luxemburg, 1981

23. H. Schraube et al. - "Proceedings of the Sixth Symposium on Neutron Dosimetry"Radiation Protection Dosimetry, Vol. 23 (1988) "Neutron Dosimetry, Proceedings of the Eight Symposium" - Radiation Protection Dosimetry, Vol. 70 (1997)

24. Eight DOE Workshop on Personnel Neutron Dosimetry, Batelle, June 1981 Ninth DOE Workshop on Personnel Neutron Dosimetry, Batelle, December 1982

25. NCRP Report 38 - "Protection Against Neutron Radiation". Bethesda MD, January 1971

26. ICRU Report 43 - "Determination of Dose Equivalents Resulting from External Radiation Sources". Bethesda MD 20814, February 1985

27. NCRP Report 91 - "Recommendations on Limits for Exposure to Ionizing Radiation". Bethesda MD, June 1987

28. ICRP Publication 60 - " 1990 Recommendations of the International Commission on Radiological Protection”, Pergamon Press, 1991

29. ICRU Report 40 - “ The Quality Factor in Radiation Protection”, 1986

30. CIRRPC Science Panel Report No. 10 - "Neutron Quality Factor" - Committee on Interagency Radiation Research and Policy Coordination, Office of Science and Technology Policy, Office of the President, 1995

31. T. Wilcox and E. Lent - "COG - A Particle Transport Code Designed to Solve the Boltzman Equation for Deep-Penetration (Shielding) Problems", Vol. 1 Users Manual, LLNL Rept. \# M-221-1 (1989); see also R. Buck and E. Lent - "COG: A New, High-Resolution Code for Modeling Radiation Transport," LLNL Energy and Technology Review (June 1993); additional information on COG may be obtained 
at URL $\quad$ http://www-phys.llnl.gov/N Div/COG/.

32. T. Wilcox and E. Lent - "COG - A Particle Transport Code Designed to Solve the Boltzman Equation for Deep-Penetration (Shielding) Problems", Vol. 4: Benchmark Problems, LLNL Rept. \# M-221-4 (1989). 


\begin{abstract}
APPENDIX 1
This Appendix has been included to indicate some of the problems and considerations involved in the selection and calibrations of dosimeters to be used in a neutron dosimetry program. There are number of review papers and proceedings of meetings on personnel neutron dosimetry [9-15].

The following paragraphs are taken from the latest ANSI standard on personnel neutron dosimeters [1]. "In recent years there has been a great deal of controversy surrounding the best choice for the quality factor to be used for personnel exposures to neutrons. The National Council on Radiation Protection and Measurements (NCRP) recommended in Report 38 [16] a table of fluence to dose equivalent factors that were derived from an explicit relationship between the quality factor and the LET of the secondary charged particles produced from neutron interactions in soft tissue. The report noted that a conservative assessment of the dose equivalent could be made by employing an approximate factor of 10 .
\end{abstract}

In 1985, the International Committee for Radiation Protection (ICRP) recommended [17] an increase in the approximate value of the quality factor for neutrons by a factor of two based on more current information on the biological effectiveness of neutrons (see also the second note under Table 2 on the next page). In 1987 the NCRP [18] endorsed this change and recommended that the factor of two be applied at all neutron energies. In 1993, the NCRP reaffirmed its 1987 recommendation and adopted the concept of the radiation weighting factor, $w_{R}$, proposed by the ICRP [19]. In a report [20] published by the International Commission on Radiation Units and measurements (ICRU), a joint ICRU/ICRP Task Group recommended a new definition of the quality factor in terms of the linear energy of the secondary charged particles produced from neutron interactions with ICRU tissue.

In June 1995, the Committee on Interagency Radiation Research and Policy Coordination (CIRRPC) reviewed the controversy surrounding the appropriate choice of the quality facotr and recommended that "present values of the absorbed dose or dose equivalent relationships for neutrons, nominally $Q_{n}$ value of 10 , by Federal agencies should be maintained until such as need for change is firmly established." [21]. The recommended increase in the quality factor remains controversial." 
TABLE 1

Neutron Quality Factors

\begin{tabular}{|c|c|c|}
\hline $\begin{array}{l}\text { Neutron Energy } \\
\text { (MeV }\end{array}$ & $\begin{array}{c}\text { U.S. } \\
\text { 10CFR835 }(1998) \\
\text { and NCRP } 38(1985)\end{array}$ & $\begin{array}{l}\text { Russian } \\
\text { NRB-99 }\end{array}$ \\
\hline $2.5 \times 10^{-8}$ thermal & 2 & \multirow{6}{*}{5} \\
\hline $1 \times 10^{-7}$ & 2 & \\
\hline $1 \times 10^{-6}$ & 2 & \\
\hline $1 \times 10^{-5}$ & 2 & \\
\hline $1 \times 10^{-4}$ & 2 & \\
\hline $1 \times 10^{-3}(1 \mathrm{keV})$ & 2 & \\
\hline $1 \times 10^{-2}(10 \mathrm{keV})$ & 2.5 & \multirow[t]{2}{*}{10} \\
\hline $1 \times 10^{-1}(100 \mathrm{keV})$ & 7.5 & \\
\hline $5 \times 10^{-1}(500 \mathrm{keV})$ & 11 & \multirow{3}{*}{20} \\
\hline 1 & 11 & \\
\hline 2.5 & 9 & \\
\hline 5 & 8 & \multirow{5}{*}{10} \\
\hline 7 & 7 & \\
\hline 10 & 6.5 & \\
\hline 14 & 7.5 & \\
\hline 20 & 8 & \\
\hline 40 & 7 & \multirow{3}{*}{5} \\
\hline 60 & 5.5 & \\
\hline 100 & 4 & \\
\hline
\end{tabular}

Note:U.S. Q factors are defined as the maximum value in a $30 \mathrm{~cm}$ dosimetry phantom. Russian NRB-99 Q factors are defined for neutron "radiation incident on a human body".

Note:The International Commission on Radiation Protection (ICRP) issued the following statement from its meeting in Paris during March 1985 on the value of the quality factor in case of neutrons (ICRP, 1985b).

"The information now available on the relative biological effectiveness (RBE) for neutrons for a variety of cellular effects in vitro, and for life shortening in the mouse, is being reviewed by the Commission. The implications of this information will be considered as part of a larger review of recommendations to be undertaken by the Commission over the next four or so years. Meanwhile, in the case of neutrons, the Commission recommends an increase in $\mathrm{Q}$ by a factor of 2 . The permitted approximation for $Q$ for fast neutrons thus changes from 10 to 20 . This changes relate only to neutrons, and no other changes are recommended at this time."

Since the change in $\mathrm{Q}$ for neutrons may not be introduced into all national procedures at the same time, it seems appropriate for statements of the dose equivalent to indicate whether the change have been applied. 
TABLE 2

Values for the effective dose and allowable average annual flux density of monoenergetic neutrons for personnel in connection with external irradiation of the whole body from NRB-99 (Russian Radiation Safety Code - 1999)

\begin{tabular}{|c|c|c|c|c|}
\hline \multirow{2}{*}{$\begin{array}{c}\text { Neutron } \\
\text { energy, MeV }\end{array}$} & \multicolumn{2}{|c|}{\begin{tabular}{c} 
Effective dose per unit fluence, \\
$10^{-12}$ \\
\cline { 2 - 5 }
\end{tabular}} & $\mathrm{SRF}^{*} \cdot \mathrm{cm}^{2}$ & \multicolumn{2}{c|}{$\begin{array}{c}\text { Allowable average annual flux } \\
\text { density, } \mathrm{AFD}_{\text {personnel }} \mathrm{cm}^{-2} \cdot \mathrm{c}^{-1}\end{array}$} \\
\cline { 2 - 5 } $\begin{array}{c}\text { Thermal } \\
\text { neutrons }\end{array}$ & 3.30 & 7.60 & $9.90+2$ & $4.30+2$ \\
\hline $1.0-7$ & 4.13 & 9.95 & $7.91+02$ & $3.28+02$ \\
\hline $1.0-6$ & 5.63 & $1.38+1$ & $5.80+02$ & $2.37+02$ \\
\hline $1.0-5$ & 6.44 & $1.51+1$ & $5.07+02$ & $2.16+02$ \\
\hline $1.0-4$ & 6.45 & $1.46+1$ & $5.07+02$ & $2.24+02$ \\
\hline $1.0-3$ & 6.04 & $1.42+1$ & $5.41+02$ & $2.30+02$ \\
\hline $1.0-2$ & 7.70 & $1.83+1$ & $4.24+02$ & $1.79+02$ \\
\hline $2.0-2$ & $1.02+1$ & $2.38+1$ & $3.20+02$ & $1.37+02$ \\
\hline $5.0-2$ & $1.73+1$ & $3.85+1$ & $1.89+02$ & $8.49+01$ \\
\hline $1.0-1$ & $2.72+1$ & $5.98+1$ & $1.20+02$ & $5.46+01$ \\
\hline $2.0-1$ & $4.24+1$ & $9.90+1$ & $7.71+01$ & $3.30+01$ \\
\hline $5.0-1$ & $7.50+1$ & $1.88+2$ & $4.36+01$ & $1.74+01$ \\
\hline 1.0 & $1.16+2$ & $2.82+2$ & $2.82+01$ & $1.16+01$ \\
\hline 1.2 & $1.30+2$ & $3.10+2$ & $2.51+01$ & $1.05+01$ \\
\hline 2.0 & $1.78+2$ & $3.83+2$ & $1.84+01$ & 8.53 \\
\hline 3.0 & $2.20+2$ & $4.32+2$ & $1.49+01$ & 7.56 \\
\hline 4.0 & $2.50+2$ & $4.58+2$ & $1.31+01$ & 7.13 \\
\hline 5.0 & $2.72+2$ & $4.74+2$ & $1.20+01$ & 6.89 \\
\hline 6.0 & $2.82+2$ & $4.83+2$ & $1.16+01$ & 6.76 \\
\hline 7.0 & $2.90+2$ & $4.90+2$ & $1.13+01$ & 6.67 \\
\hline 8.0 & $2.97+2$ & $4.94+2$ & $1.10+01$ & 6.61 \\
\hline 10 & $3.09+2$ & $4.99+2$ & $1.06+01$ & 6.55 \\
\hline 14 & $3.33+2$ & $4.96+2$ & 9.81 & 6.59 \\
\hline 20 & $3.43+2$ & $4.80+2$ & 9.52 & 6.81 \\
\hline
\end{tabular}

* IRF represents the isotropic $(4 \pi)$ radiation field; F-B, parallel-beam irradiation with front-to-back geometry

In the table an entry of the type $1.6-12$ shall designate $1.6 \times 10^{-12}$, and $1.6+12$ shall designate $1.6 \times 10^{+12}$. 
TABLE 3

\section{Neutron Dose Summary}

\begin{tabular}{|c|c|c|c|c|c|}
\hline Location & $\begin{array}{c}\text { Int. Spectrum } \\
\text { [neutrons/cm^2] }\end{array}$ & $\begin{array}{c}\text { Int. Dose-U.S.'77 } \\
\text { [rem/neutron] }\end{array}$ & $\begin{array}{c}\text { Int. Dose-U.S.'91 } \\
\text { [rem/neutron] }\end{array}$ & $\begin{array}{l}\text { Int. IRF - Russ. } \\
\text { [rem/neutron] }\end{array}$ & $\begin{array}{l}\text { Int. F-B - Russ. } \\
\text { [rem/neutron] }\end{array}$ \\
\hline \multicolumn{6}{|l|}{$\begin{array}{c}\text { Bare source spectrum (@ } 1 \\
\text { m) }\end{array}$} \\
\hline \multicolumn{3}{|l|}{$\begin{array}{c}\text { BDMS spectrum (shutter } \\
\text { open) }\end{array}$} & $1.9587 E-08$ & 1.6403E-08 & 3.4162E-08 \\
\hline Location 401 & $3.1203 E+02$ & $1.7111 \mathrm{E}-08$ & 8.7058E-09 & 7.3611E-09 & 1.5821E-08 \\
\hline Location 402 & $2.3799 E+02$ & $1.9266 \mathrm{E}-08$ & 9.9260E-09 & 8.3972E-09 & 1.7957E-08 \\
\hline Location 403 & $1.5093 E+01$ & $2.4804 \mathrm{E}-08$ & $1.5067 E-08$ & $1.2566 \mathrm{E}-08$ & 2.5060E-08 \\
\hline Location 404 & $6.1280 E+01$ & 2.1940E-08 & 1.1682E-08 & 9.8446E-09 & 2.0861E-08 \\
\hline Location 405 & $4.7936 E+00$ & 1.7642E-08 & 8.8722E-09 & 7.5220E-09 & 1.6164E-08 \\
\hline Location 406 & $1.7570 E+00$ & 2.3436E-08 & $1.4243 E-08$ & 1.1871E-08 & 2.3637E-08 \\
\hline \multicolumn{6}{|l|}{$\begin{array}{l}\text { BDMS spectrum (shutter } \\
\text { closed) }\end{array}$} \\
\hline Location 401 & $2.5519 \mathrm{E}+02$ & 1.9198E-08 & 9.8459E-09 & 8.3321E-09 & 1.7851E-08 \\
\hline Location 402 & $2.5181 E+02$ & 1.8335E-08 & $9.3508 \mathrm{E}-09$ & 7.9143E-09 & 1.6984E-08 \\
\hline Location 403 & $1.4642 \mathrm{E}+01$ & $2.4806 \mathrm{E}-08$ & $1.5092 E-08$ & 1.2582E-08 & $2.5084 E-08$ \\
\hline Location 404 & $6.4097 E+01$ & 2.1608E-08 & $1.1434 E-08$ & 9.6486E-09 & 2.0473E-08 \\
\hline Location 405 & $4.9932 E+00$ & $1.7060 \mathrm{E}-08$ & 8.5443E-09 & 7.2406E-09 & 1.5593E-08 \\
\hline Location 406 & $1.6437 E+00$ & $2.4344 E-08$ & 1.4807E-08 & $1.2346 \mathrm{E}-08$ & $2.4580 \mathrm{E}-08$ \\
\hline
\end{tabular}


TABLE 4 Neutron, gamma and total dose rates at different locations around BDMS

\begin{tabular}{|c|c|c|c|c|c|}
\hline Location & $\begin{array}{l}\text { Integrated } \\
\text { Spectrum }\end{array}$ & $\begin{array}{l}\text { Dose Rate } \\
\text { [mrem/hr] } \\
\text { U.S. '77 }\end{array}$ & $\begin{array}{l}\text { Dose Rate } \\
\text { [mrem/hr] } \\
\text { U.S. '91 }\end{array}$ & $\begin{array}{c}\text { Dose Rate } \\
\text { [mrem/hr] } \\
\text { Russian -IRF }\end{array}$ & $\begin{array}{l}\text { Dose Rate } \\
\text { [mrem/hr] } \\
\text { Russian F-B }\end{array}$ \\
\hline NEUTRONS & $\begin{array}{c}\text { [neutrons } / \mathrm{cm}^{\wedge} 2 / \mathrm{sec} \\
]\end{array}$ & & & & \\
\hline $\begin{array}{l}\text { IAEA ref. Cf-252 source @ } 1 \text { m } \\
\text { BDMS spectrum (shutter open) }\end{array}$ & $1.9370 \mathrm{E}+01$ & $1.5798 \mathrm{E}+00$ & $9.1055 E-01$ & $7.6256 \mathrm{E}-01$ & $1.5881 E+00$ \\
\hline Location 401 & $3.1203 E+02$ & $1.2814 \mathrm{E}+01$ & $6.5196 \mathrm{E}+00$ & $5.5126 \mathrm{E}+00$ & $1.1848 E+01$ \\
\hline Location 402 & $2.3799 \mathrm{E}+02$ & $1.1004 \mathrm{E}+01$ & $5.6696 \mathrm{E}+00$ & $4.7964 E+00$ & $1.0257 E+01$ \\
\hline Location 403 & $1.5093 E+01$ & 8.9851E-01 & $5.4579 E-01$ & $4.5519 E-01$ & $9.0777 E-01$ \\
\hline Location 404 & $6.1280 E+01$ & $3.2268 E+00$ & $1.7180 E+00$ & $1.4479 E+00$ & $3.0681 E+00$ \\
\hline Location 405 & $4.7936 \mathrm{E}+00$ & 2.0297E-01 & $1.0207 E-01$ & 8.6537E-02 & $1.8597 \mathrm{E}-01$ \\
\hline \multicolumn{6}{|l|}{ BDMS spectrum (shutter closed) } \\
\hline Location 401 & $2.5519 E+02$ & $1.1757 E+01$ & $6.0301 \mathrm{E}+00$ & $5.1030 E+00$ & $1.0933 E+01$ \\
\hline Location 402 & $2.5181 E+02$ & $1.1080 E+01$ & $5.6511 E+00$ & $4.7829 E+00$ & $1.0264 E+01$ \\
\hline Location 403 & $1.4642 E+01$ & 8.7171E-01 & 5.3036E-01 & $4.4214 E-01$ & $8.8148 E-01$ \\
\hline Location 404 & $6.4097 E+01$ & $3.3240 E+00$ & $1.7589 E+00$ & $1.4843 E+00$ & $3.1494 E+00$ \\
\hline Location 405 & $4.9932 E+00$ & $2.0444 \mathrm{E}-01$ & 1.0239E-01 & 8.6768E-02 & $1.8686 \mathrm{E}-01$ \\
\hline Location 406 & 1.6437E+00 & $9.6036 \mathrm{E}-02$ & $5.8410 E-02$ & 4.8703E-02 & $9.6965 E-02$ \\
\hline GAMMA & [photons/cm^2/sec] & & & & \\
\hline $\begin{array}{l}\text { IAEA ref. Cf-252 source @ } 1 \text { m } \\
\text { BDMS (shutter open) }\end{array}$ & $1.0574 \mathrm{E}+02$ & $1.0682 \mathrm{E}-01$ & 8.7530E-02 & & \\
\hline Location 401 & $7.9952 E+02$ & 8.9735E-01 & 7.4597E-01 & & \\
\hline Location 402 & $9.4552 \mathrm{E}+02$ & $1.0258 \mathrm{E}+00$ & 8.4923E-01 & & \\
\hline Location 403 & $3.9434 \mathrm{E}+02$ & 4.7117E-01 & 3.9177E-01 & & \\
\hline Location 404 & $2.5250 E+02$ & 3.1099E-01 & 2.5973E-01 & & \\
\hline Location 405 & $3.5166 E+01$ & $3.8670 E-02$ & 3.1992E-02 & & \\
\hline Location 406 & 4.1001E+01 & 5.2391E-02 & 4.3873E-02 & & \\
\hline \multicolumn{6}{|l|}{ BDMS (shutter closed) } \\
\hline Location 401 & $7.4006 \mathrm{E}+02$ & 7.7276E-01 & 6.3555E-01 & & \\
\hline Location 402 & $8.2778 \mathrm{E}+02$ & 8.4217E-01 & $6.9122 E-01$ & & \\
\hline Location 403 & $3.6009 E+02$ & 4.1454E-01 & $3.4285 E-01$ & & \\
\hline Location 404 & $2.1942 E+02$ & 2.5289E-01 & $2.0925 E-01$ & & \\
\hline Location 405 & $3.1868 E+01$ & 3.2972E-02 & 2.7036E-02 & & \\
\hline Location 406 & $3.6972 \mathrm{E}+01$ & 4.5111E-02 & 3.7536E-02 & & \\
\hline \multicolumn{6}{|l|}{ TOTAL } \\
\hline $\begin{array}{l}\text { IAEA ref. Cf-252 source @ } 1 \text { m } \\
\text { BDMS (shutter open) }\end{array}$ & & $1.6866 \mathrm{E}+00$ & $9.9808 \mathrm{E}-01$ & & \\
\hline Location 401 & & $1.3711 E+01$ & $7.2655 E+00$ & & \\
\hline Location 402 & & $1.2030 E+01$ & $6.5188 E+00$ & & \\
\hline Location 403 & & $1.3697 E+00$ & 9.3755E-01 & & \\
\hline Location 404 & & $3.5378 E+00$ & $1.9778 E+00$ & & \\
\hline Location 405 & & $2.4164 \mathrm{E}-01$ & $1.3406 E-01$ & & \\
\hline Location 406 & & $1.5122 E-01$ & $1.0393 E-01$ & & \\
\hline \multicolumn{6}{|l|}{ BDMS (shutter closed) } \\
\hline Location 401 & & $1.2530 E+01$ & $6.6656 \mathrm{E}+00$ & & \\
\hline Location 402 & & $1.1923 E+01$ & $6.3423 E+00$ & & \\
\hline Location 403 & & $1.2863 E+00$ & 8.7321E-01 & & \\
\hline Location 404 & & $3.5769 E+00$ & $1.9681 E+00$ & & \\
\hline Location 405 & & 2.3741E-01 & 1.2943E-01 & & \\
\hline Location 406 & & 1.4115E-01 & 9.5946E-02 & & \\
\hline
\end{tabular}


Figure 1

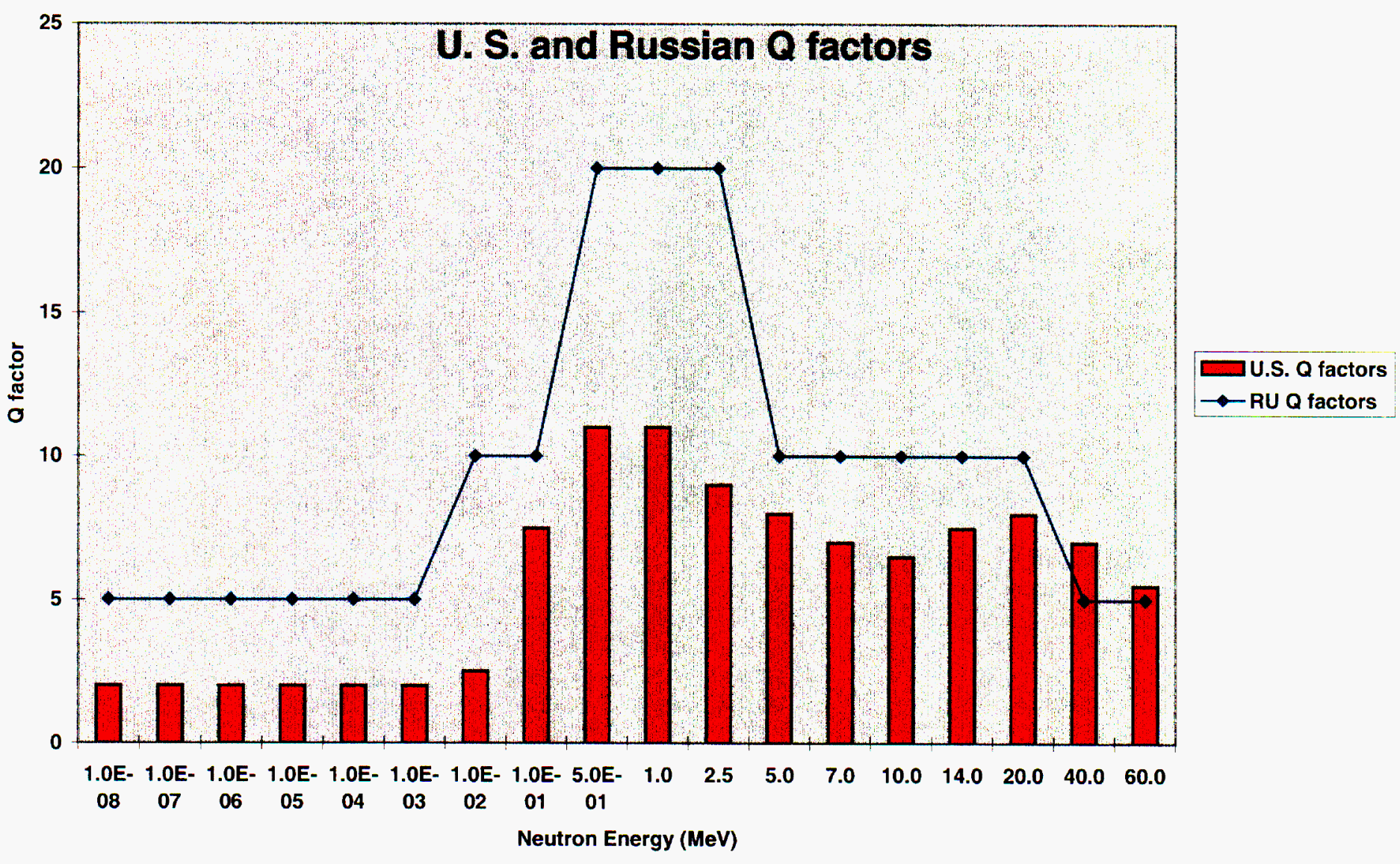


Figure 2

Top view of the BDMS, the uranium processing pipe and the numbered locations at which neutron spectra and doses are calculated

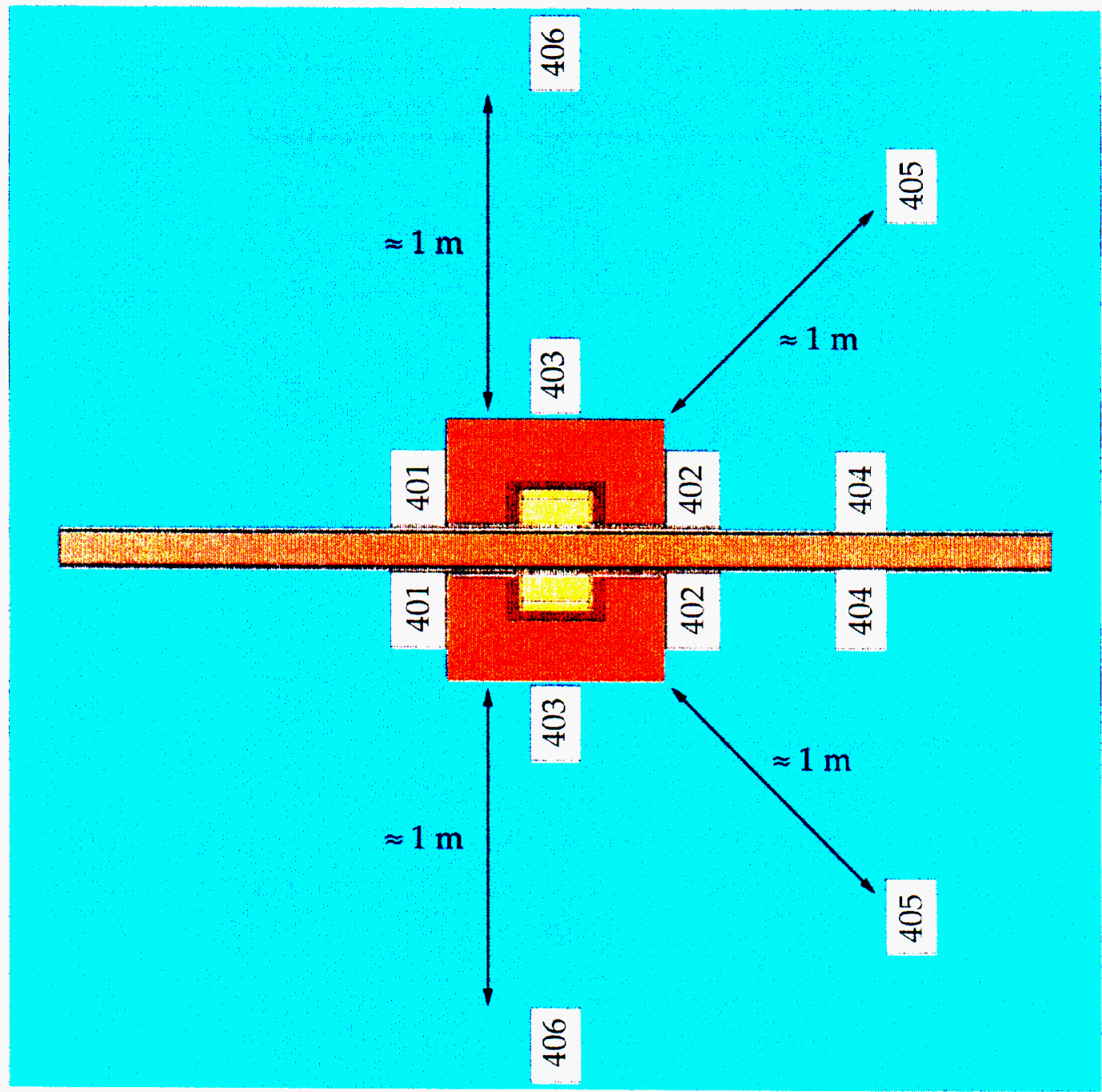


Figure 3

Normalized Neutron Energy Spectrum and Radiation Dose Curves

(shutter open, BDMS location 401)

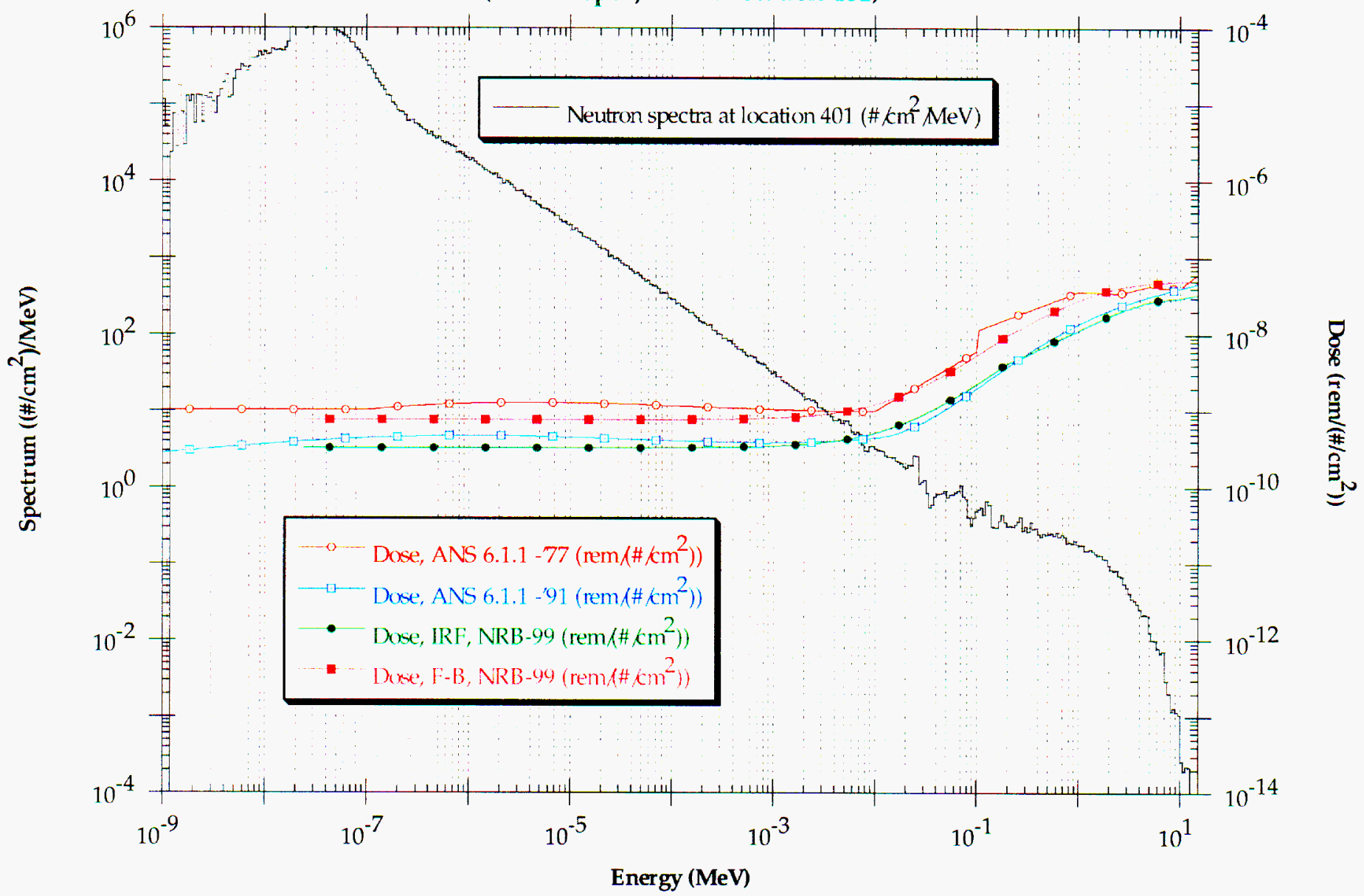




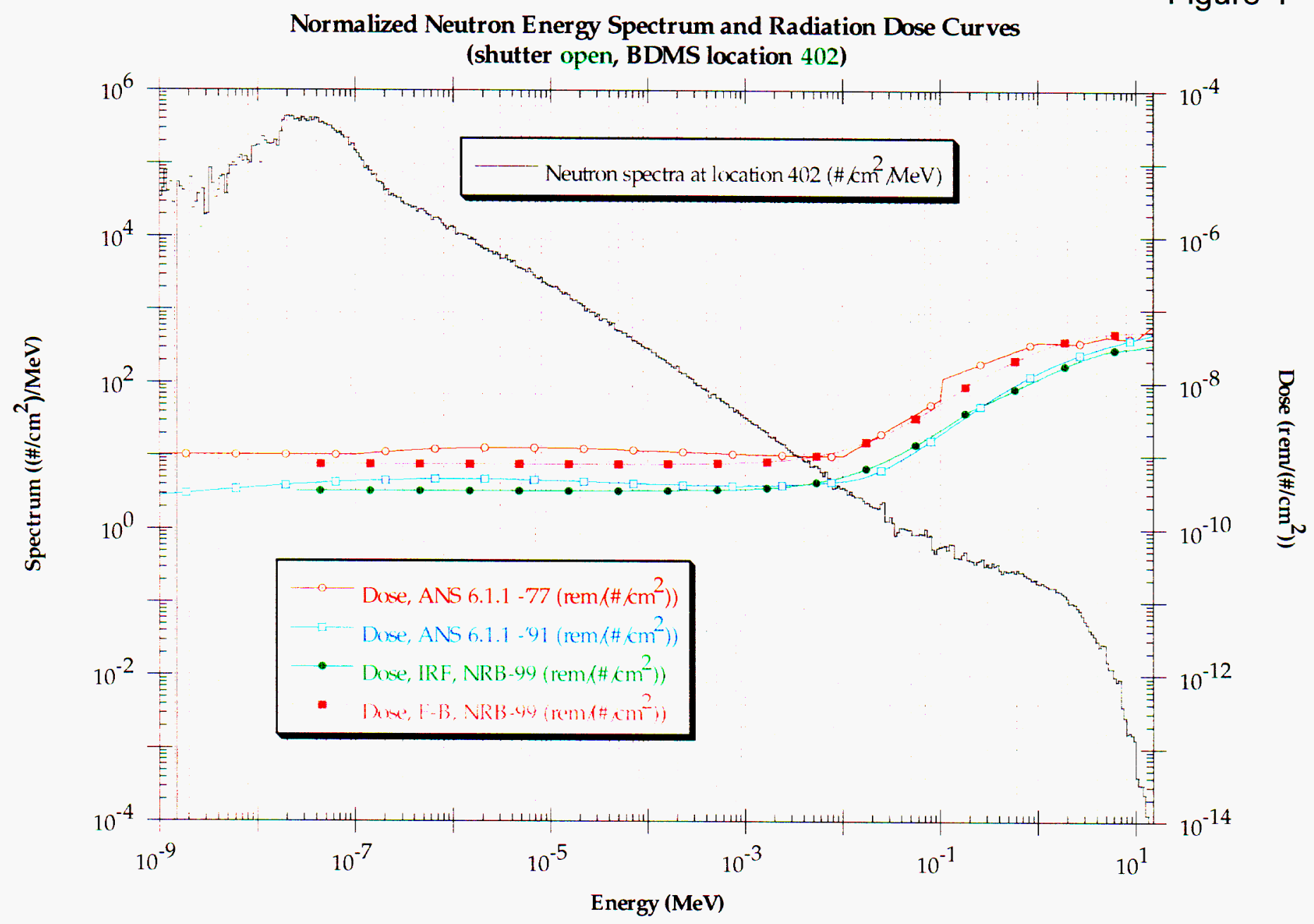


Figure 5

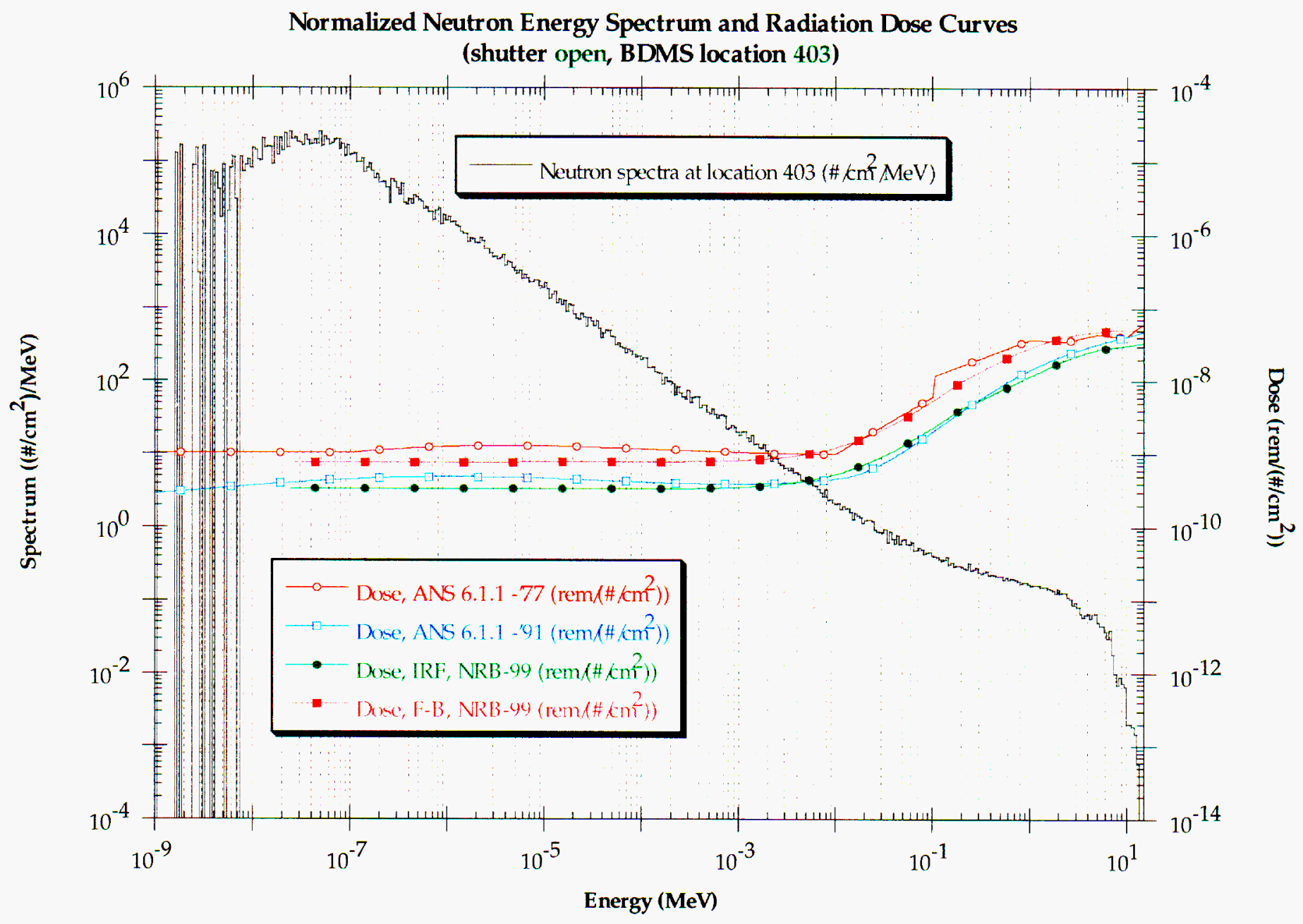


Figure 6

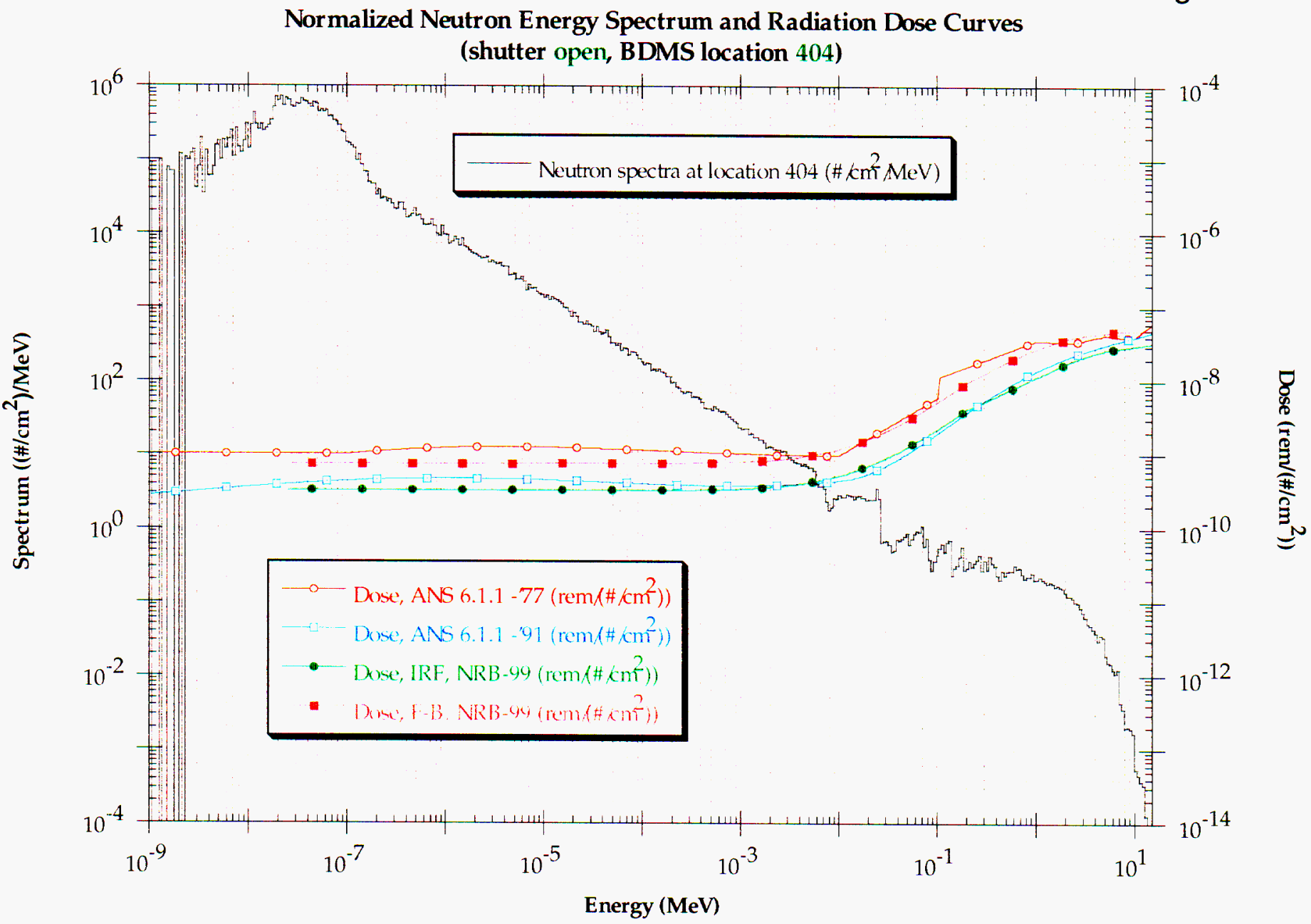


Figure 7

Normalized Neutron Energy Spectrum and Radiation Dose Curves (shutter open, BDMS location 405)

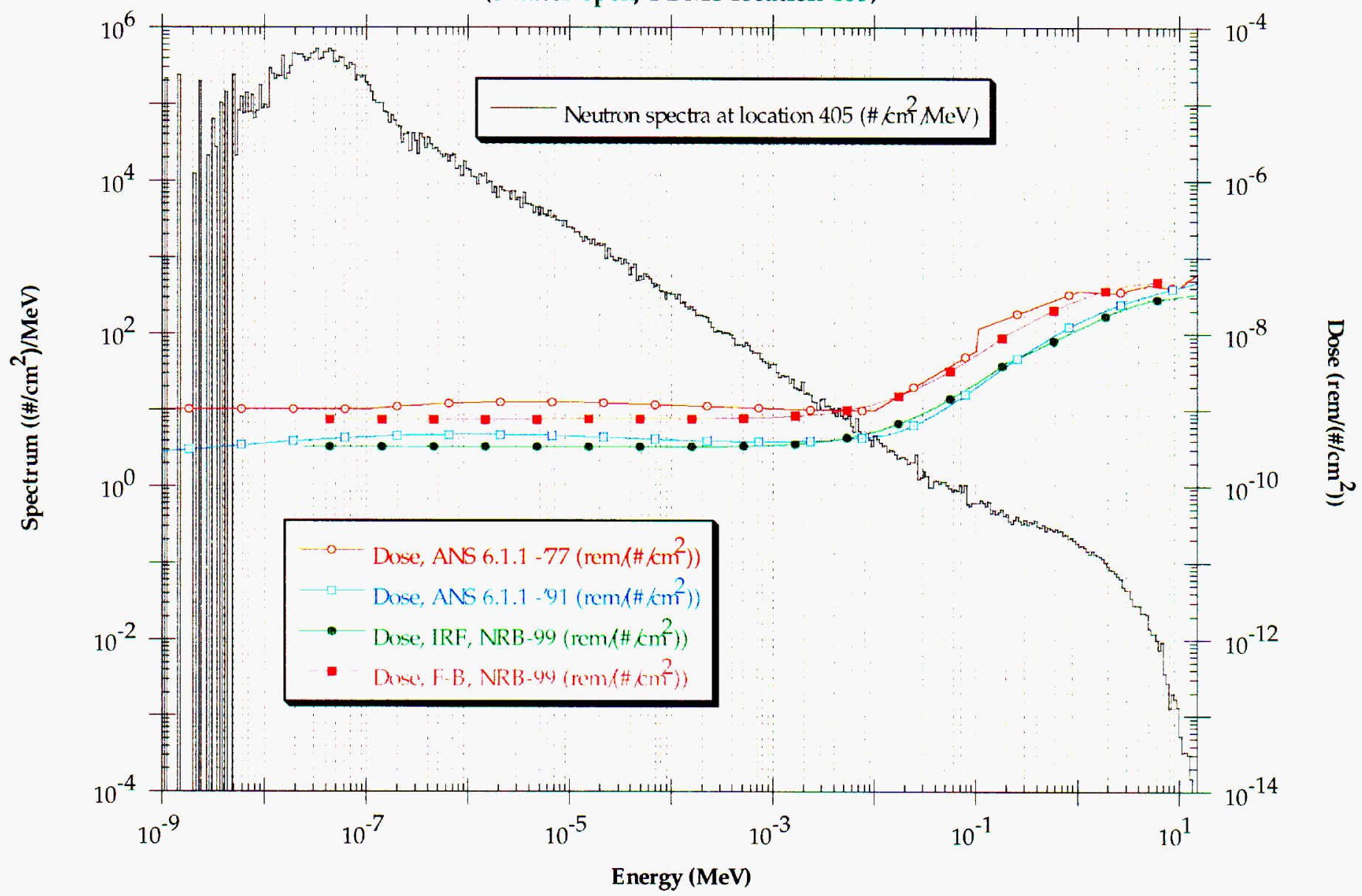




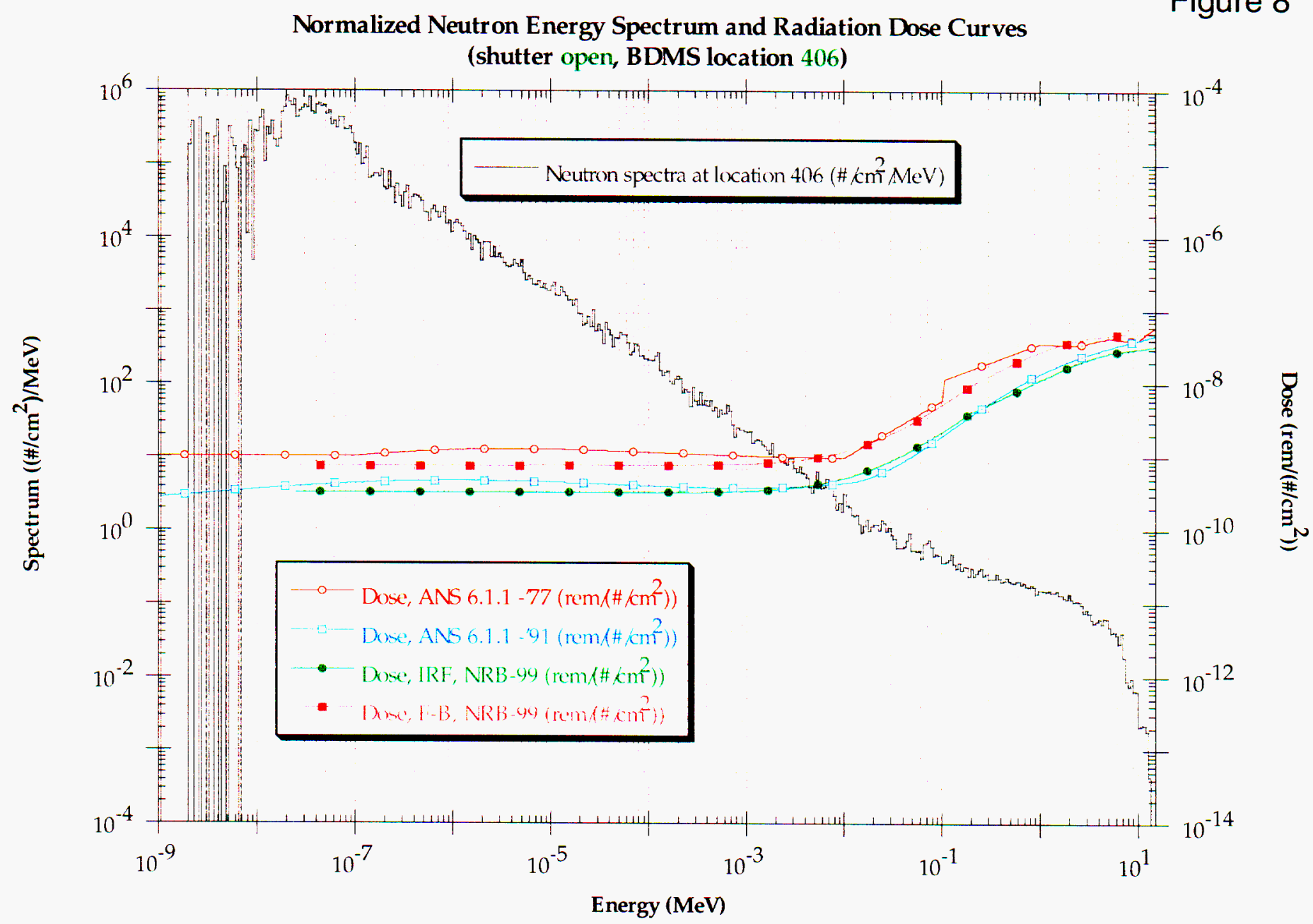


Figure 9

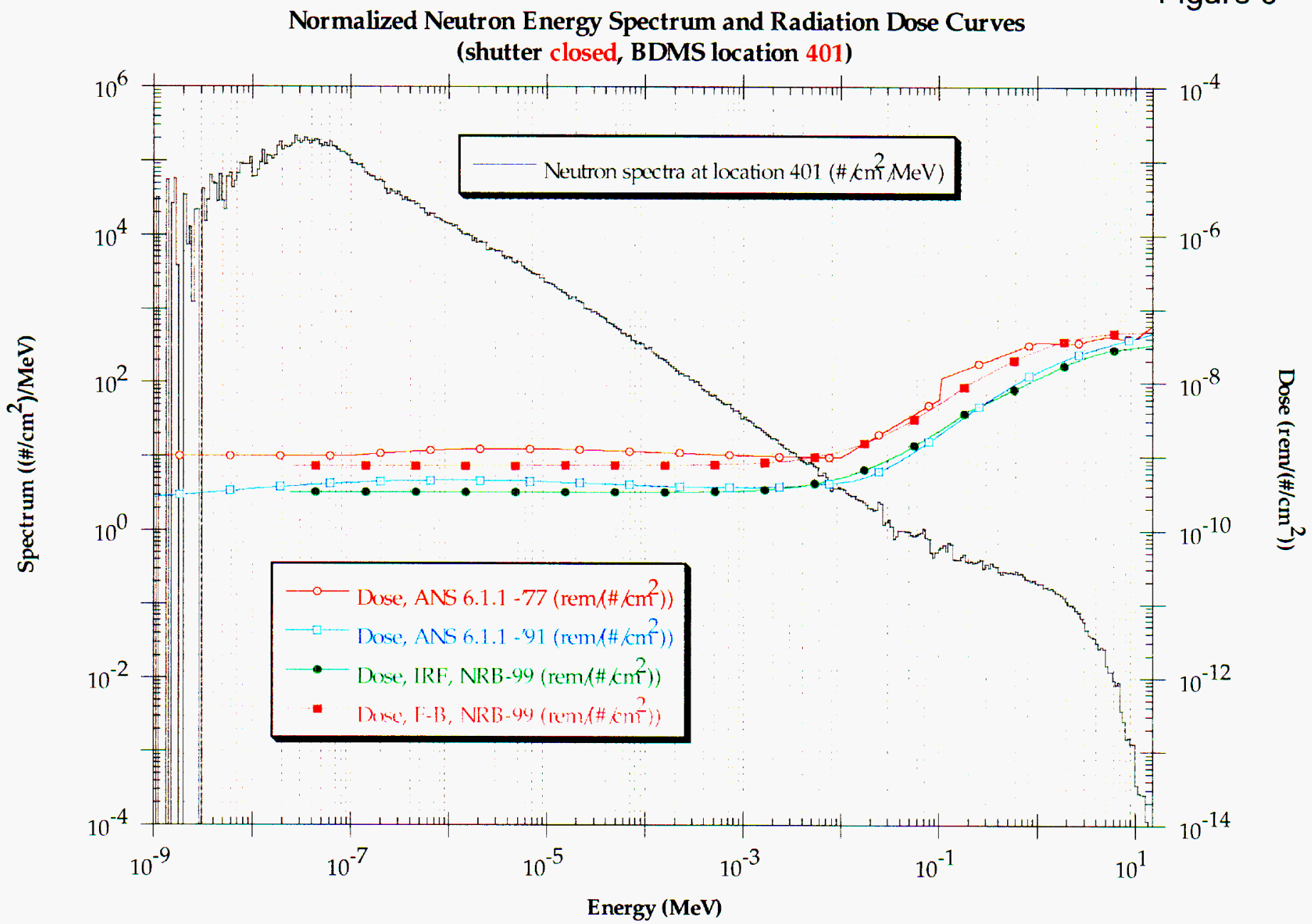




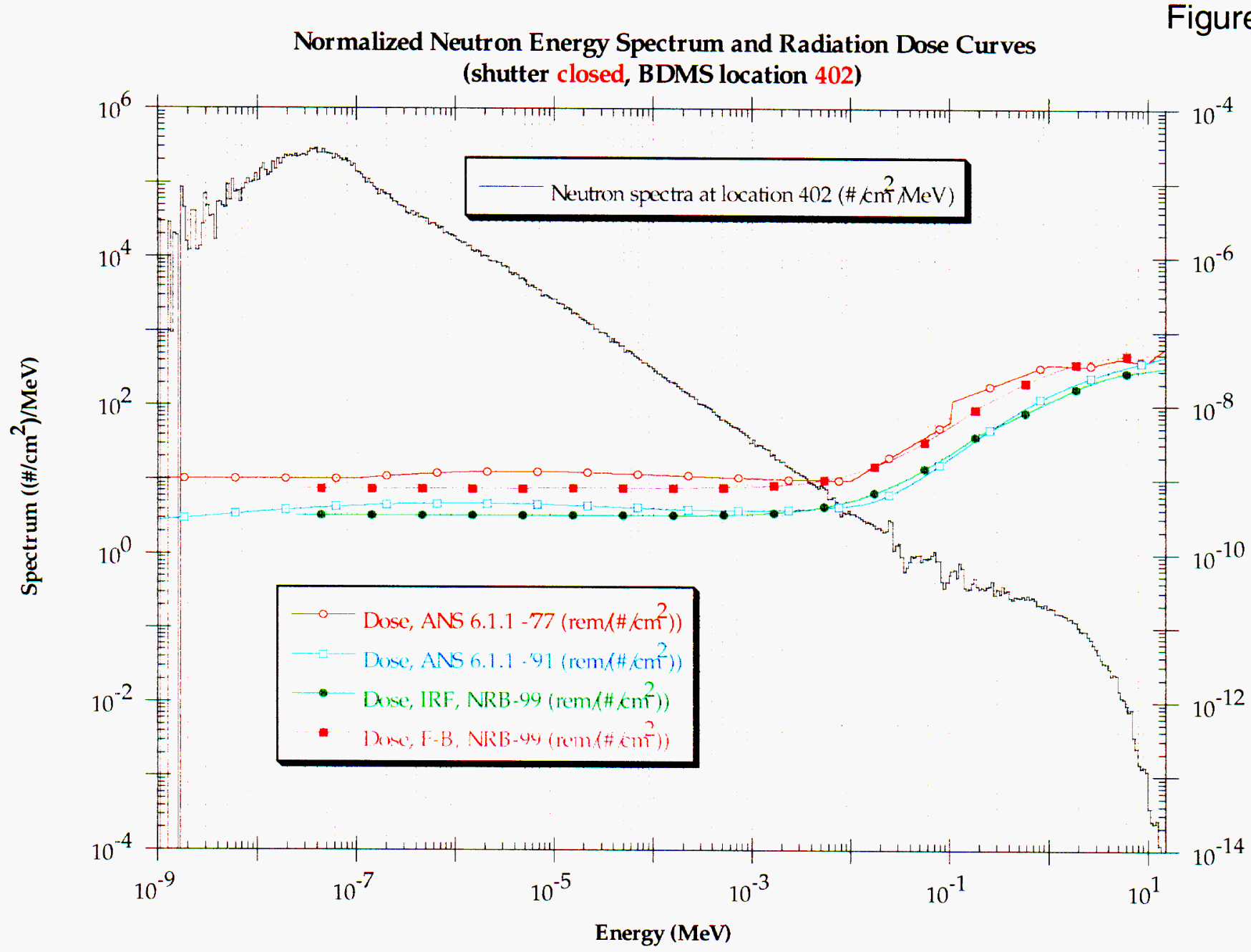


Figure 11

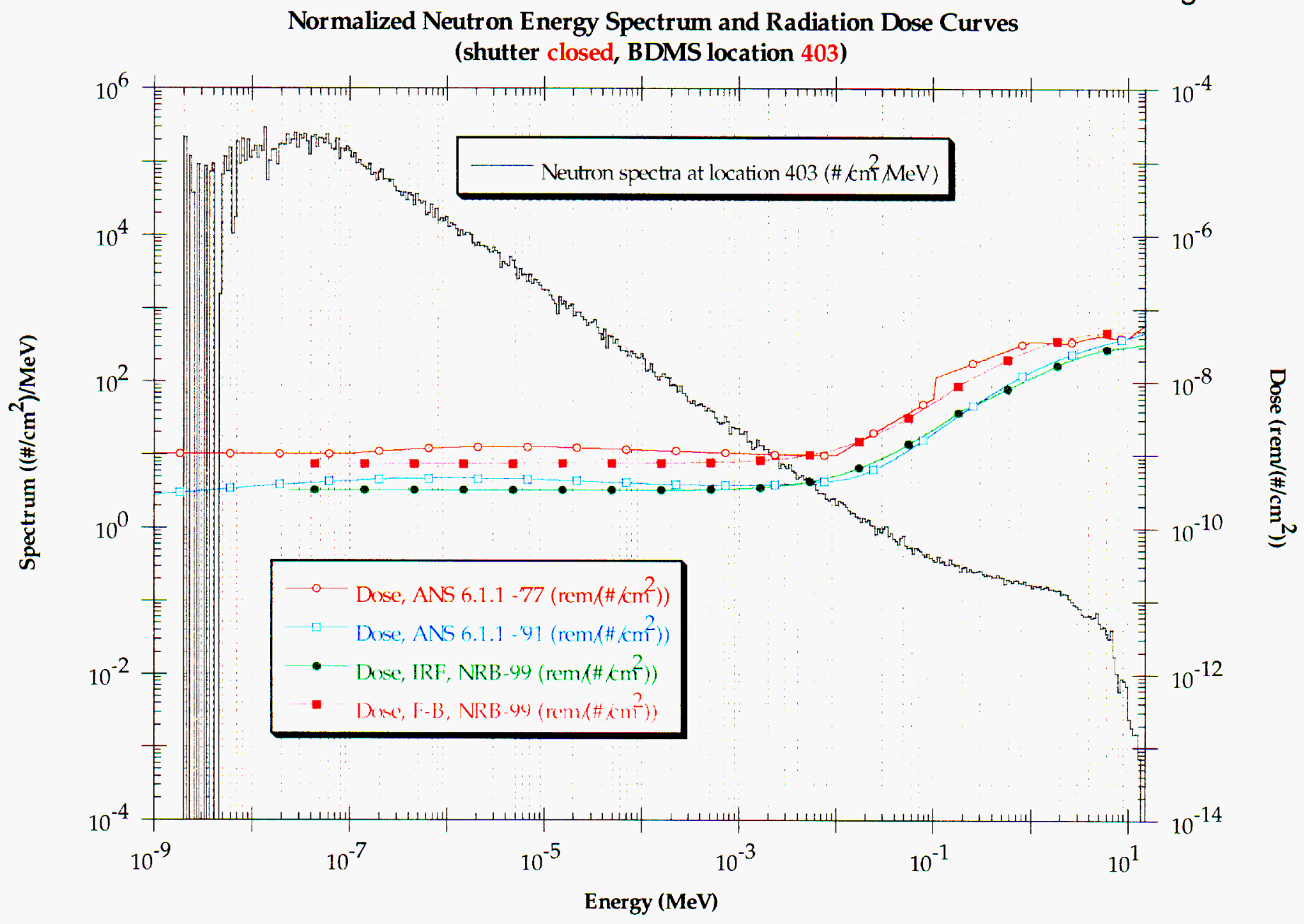




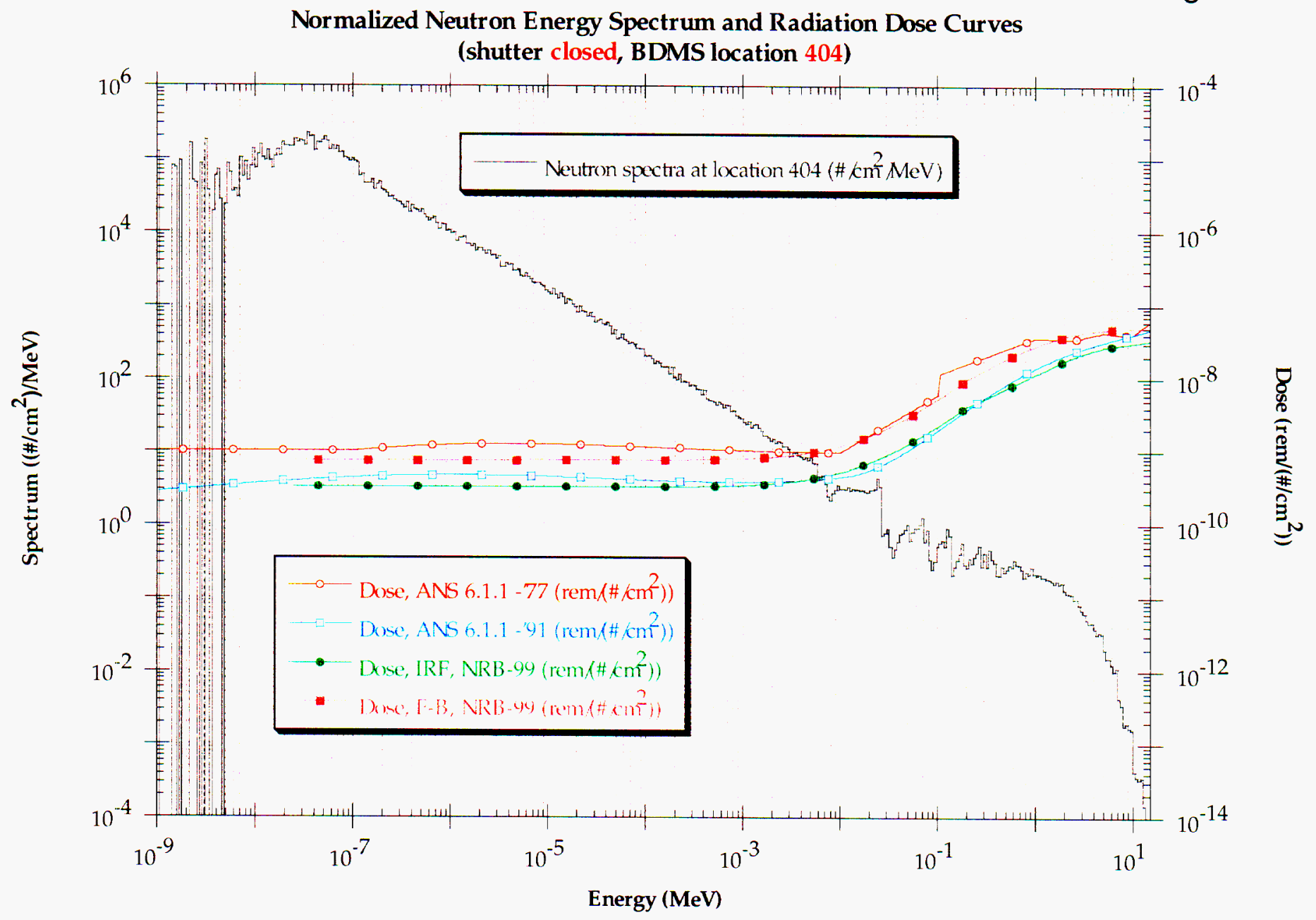


Figure 13

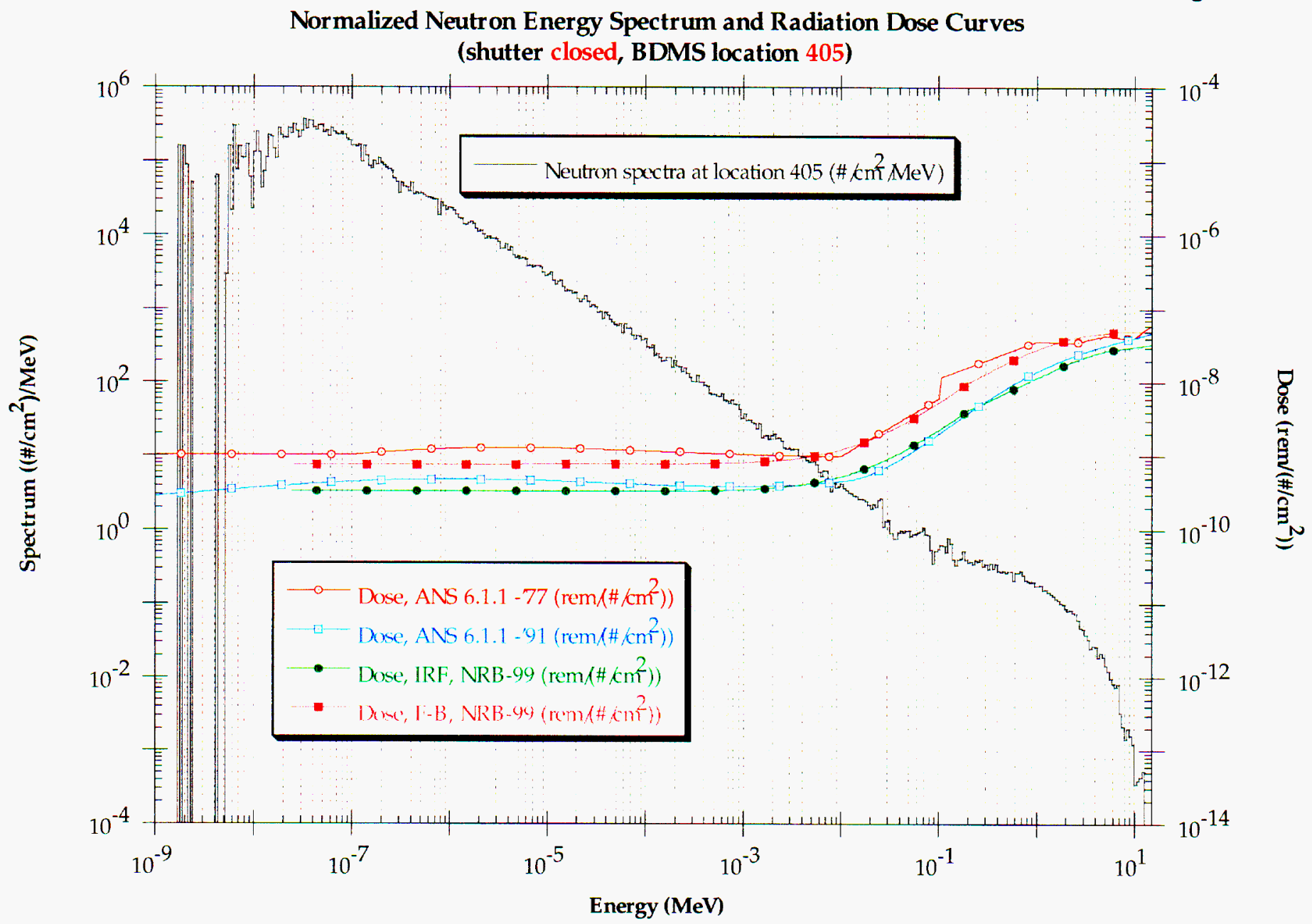


Figure 14

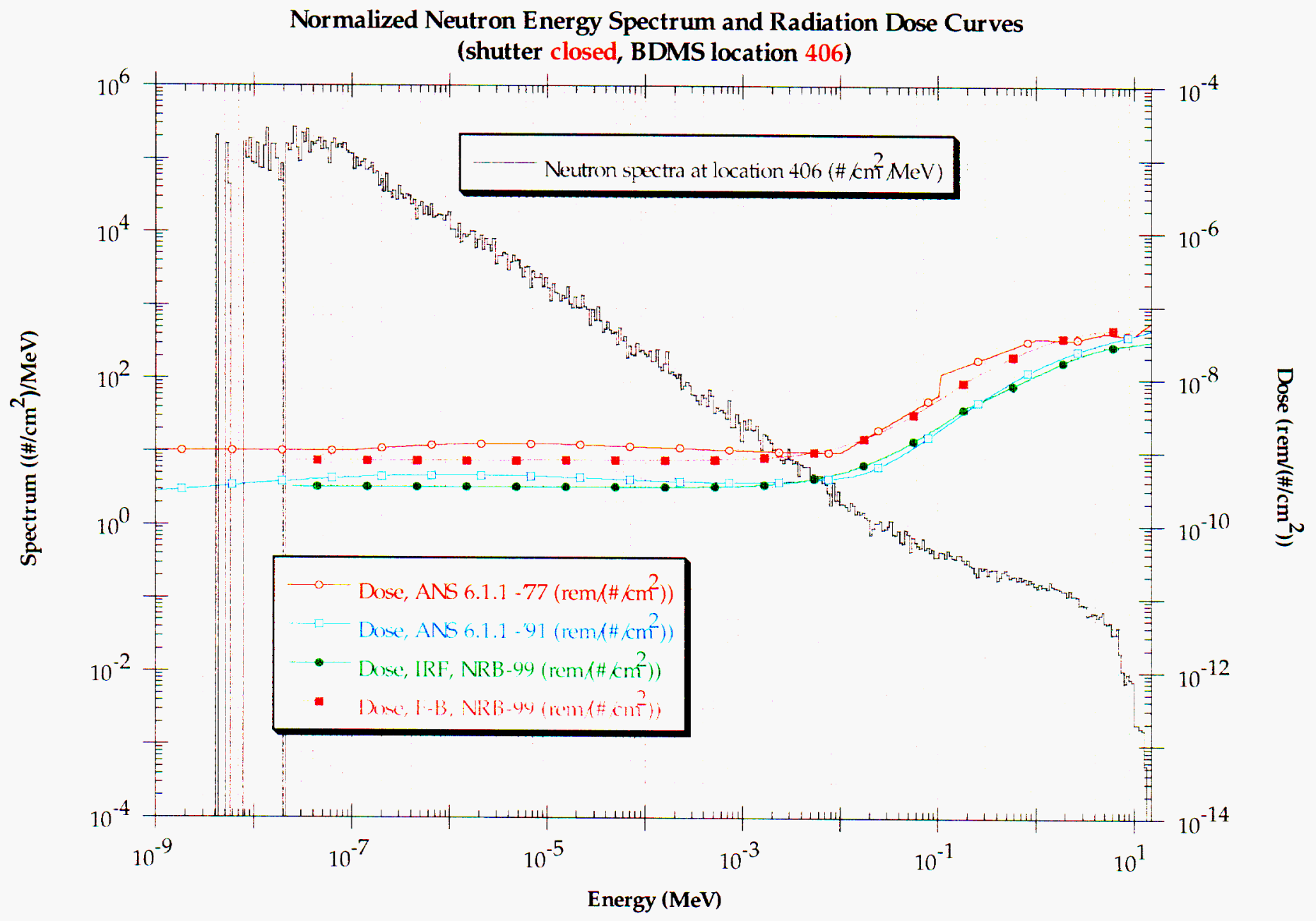


Figure 15

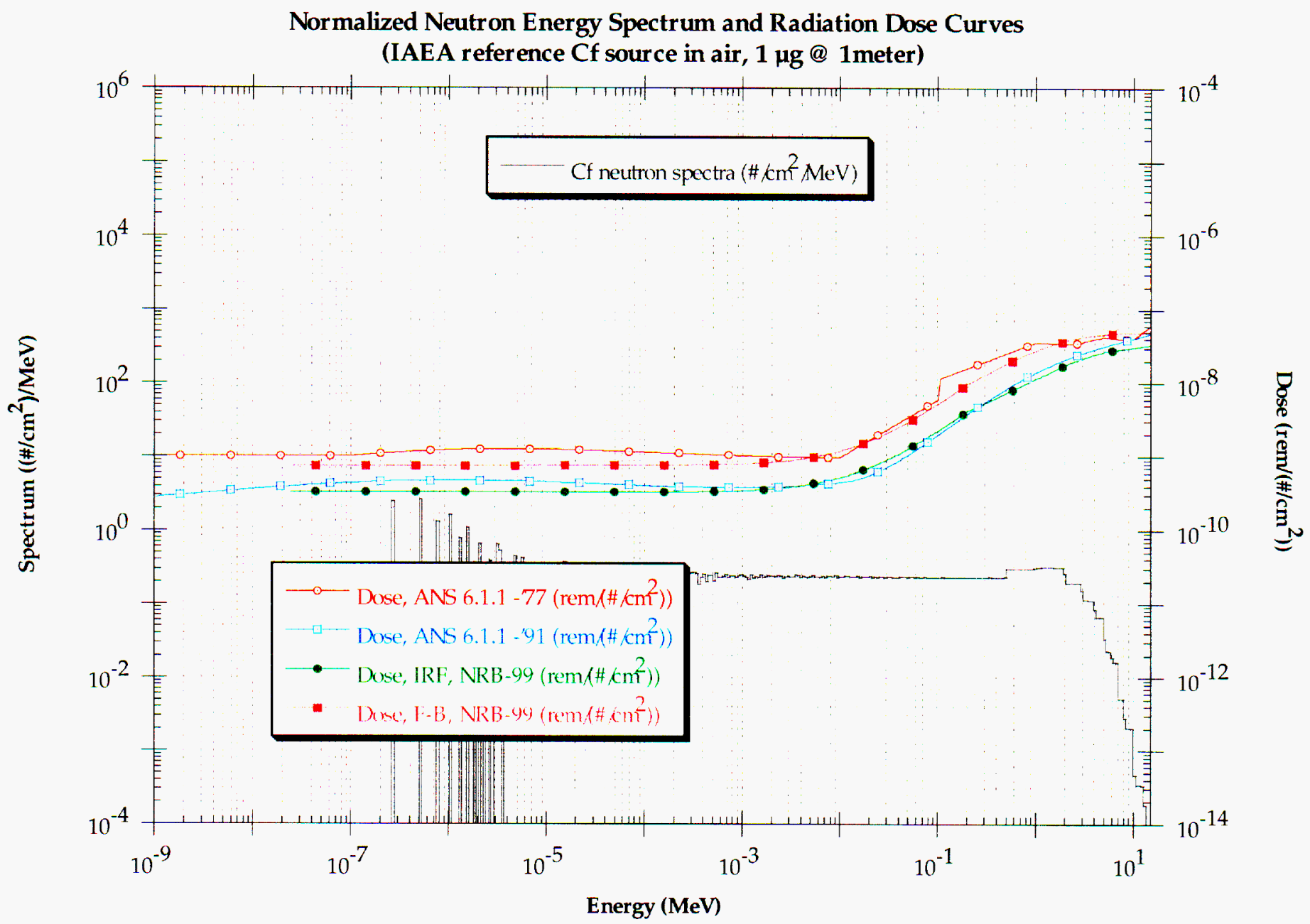


Figure 16

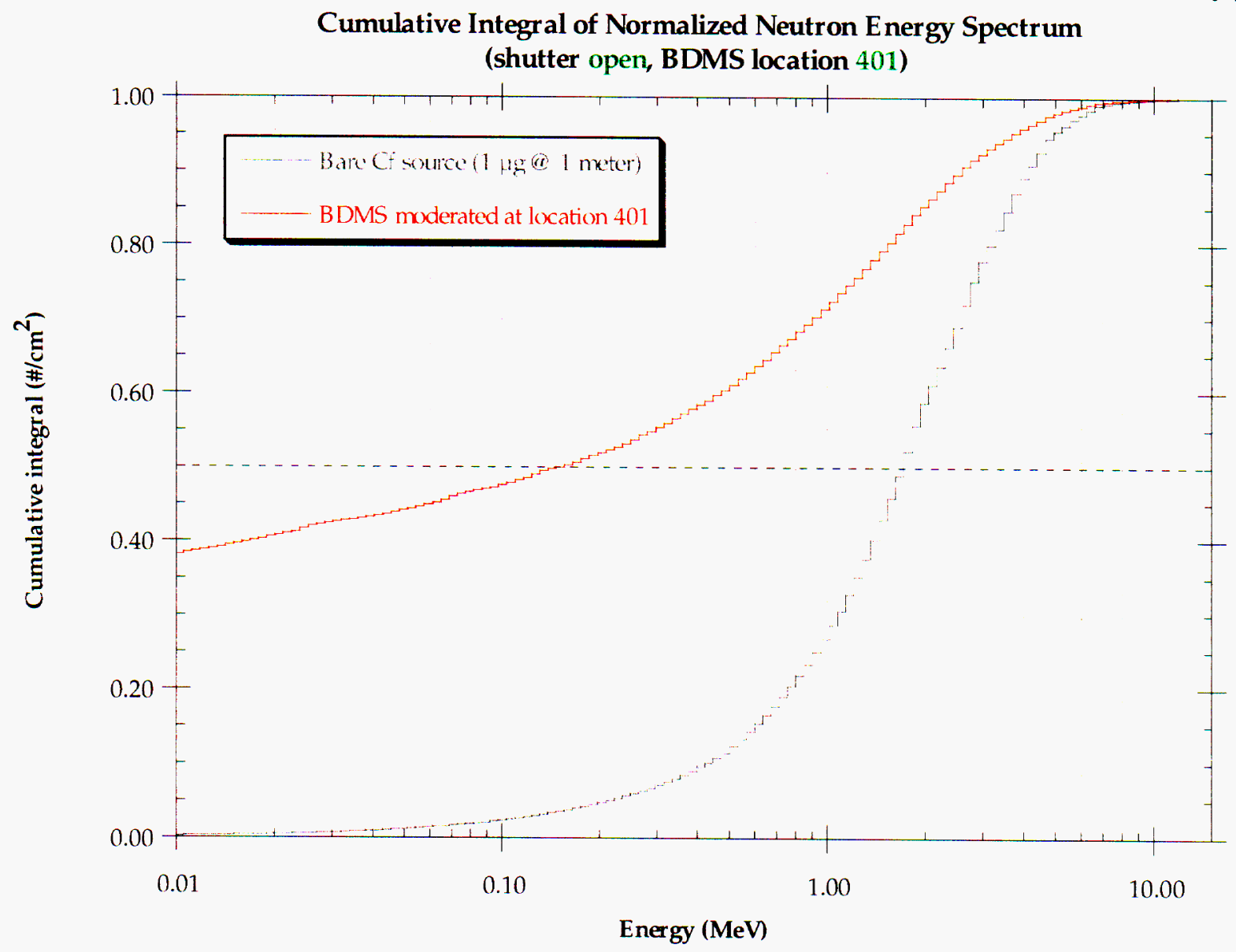




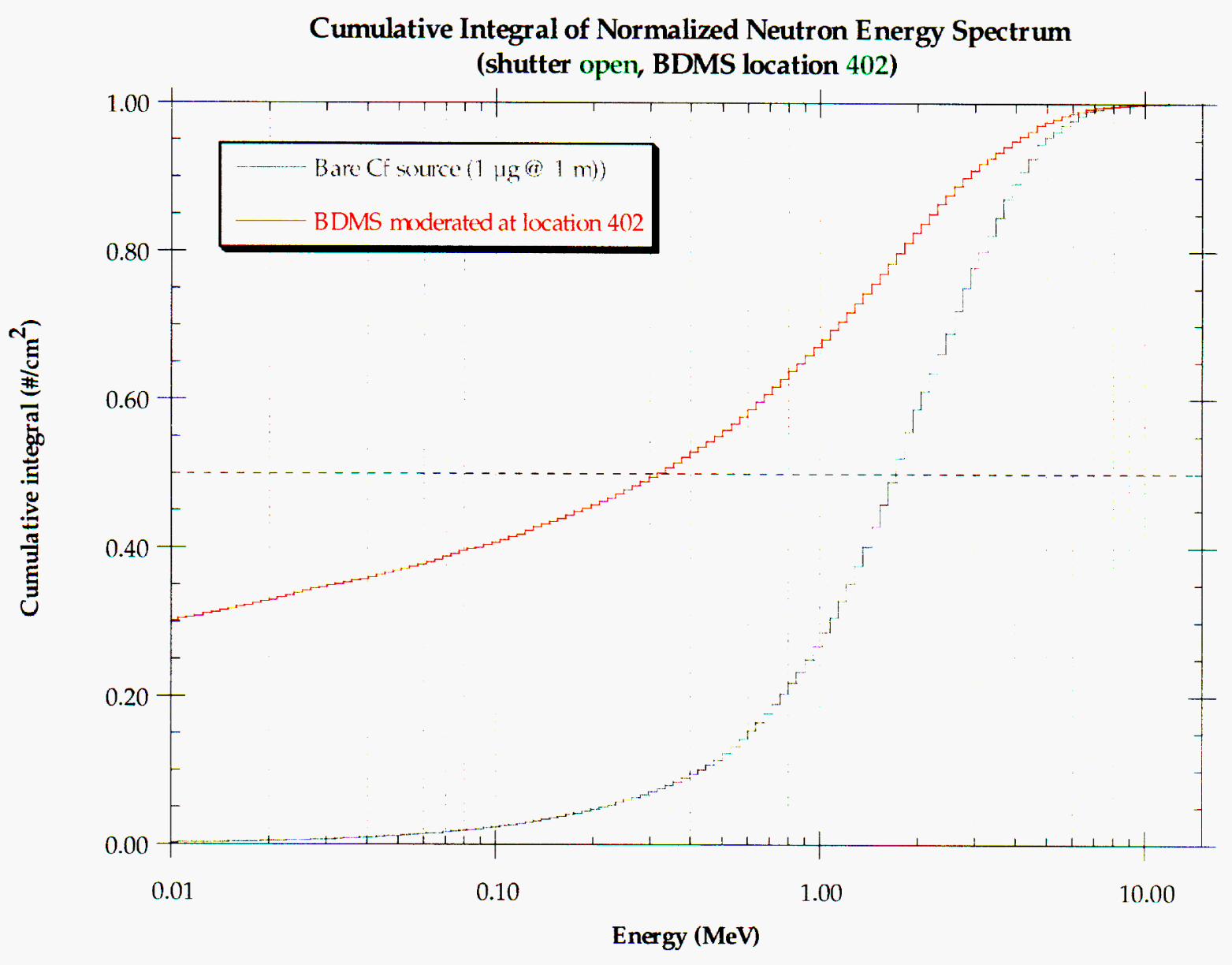


Figure 18

Cumulative Integral of Normalized Neutron Energy Spectrum (shutter open, BDMS location 403)

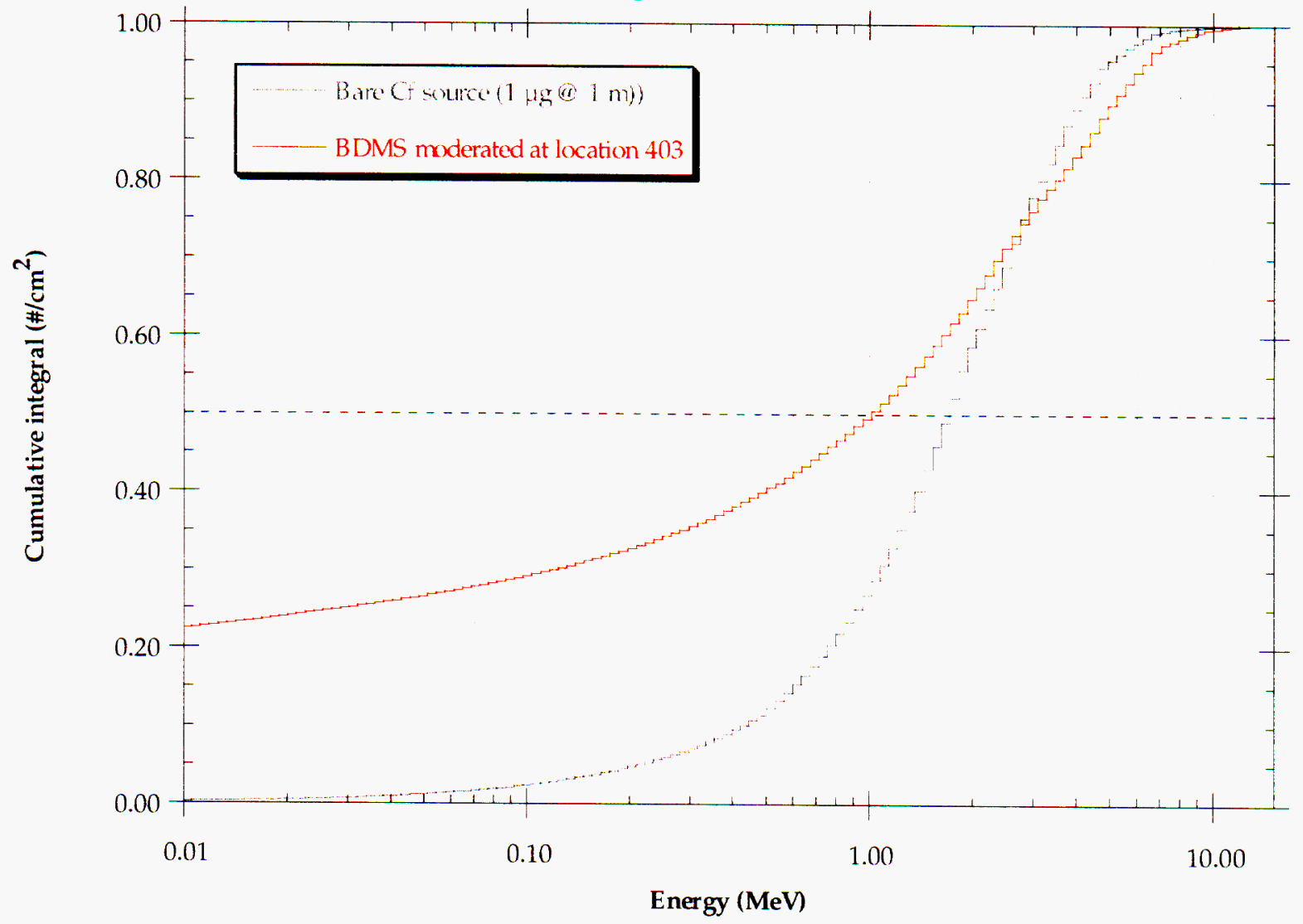


Figure 19

Cumulative Integral of Normalized Neutron Energy Spectrum (shutter open, BDMS location 404)

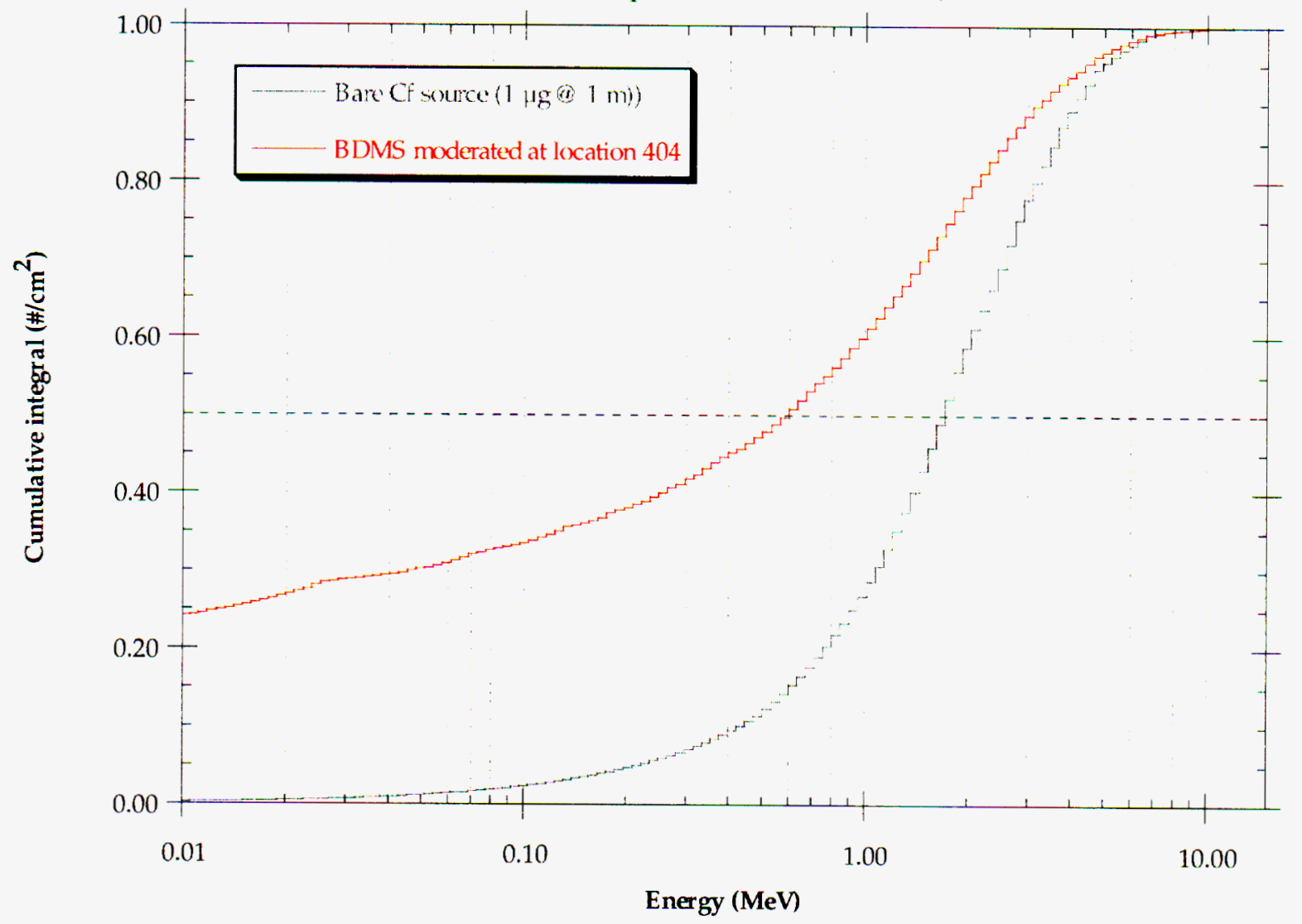


Figure 20

\section{Cumulative Integral of Normalized Energy Spectrum} (shutter open, BDMS location 405)

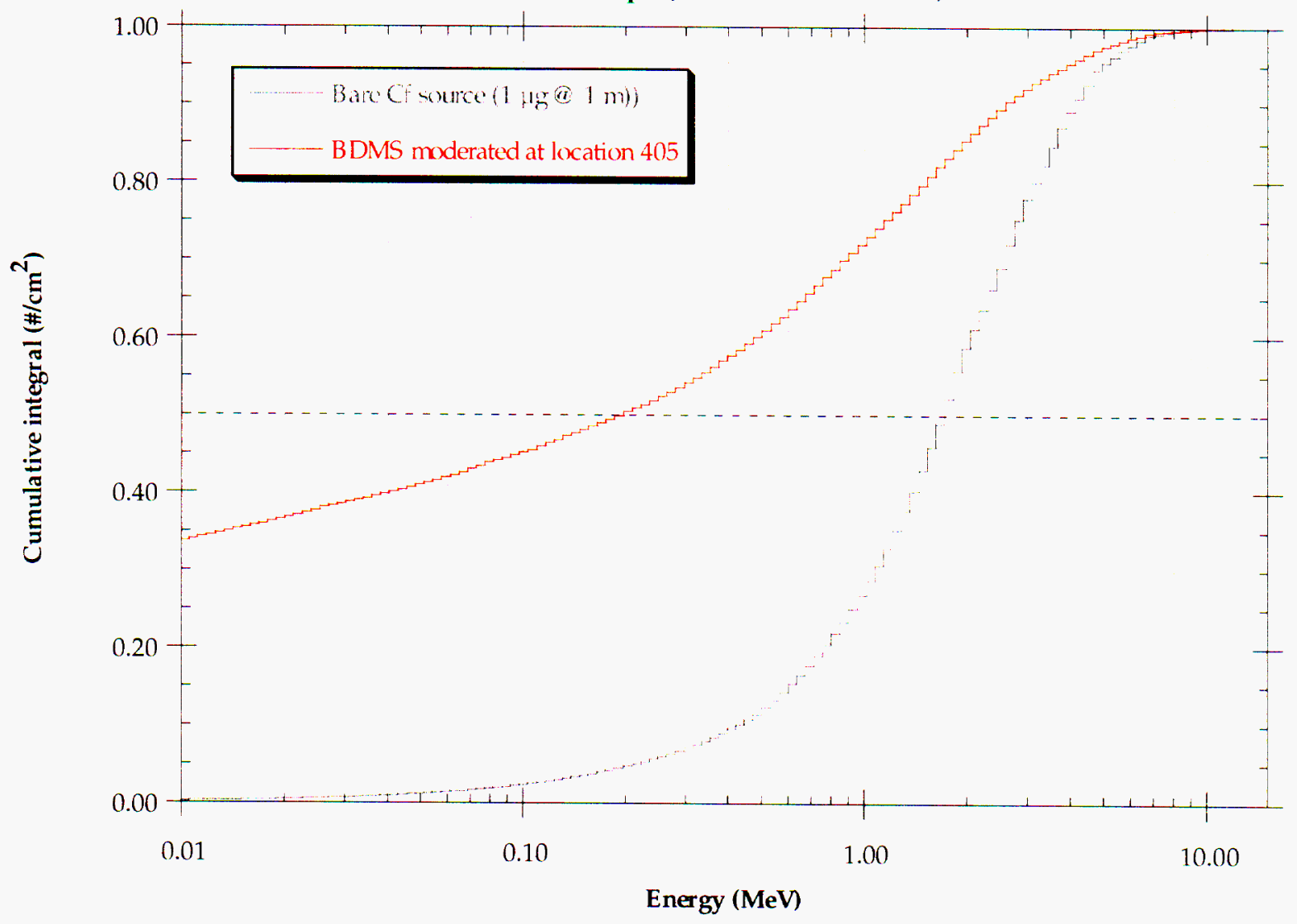




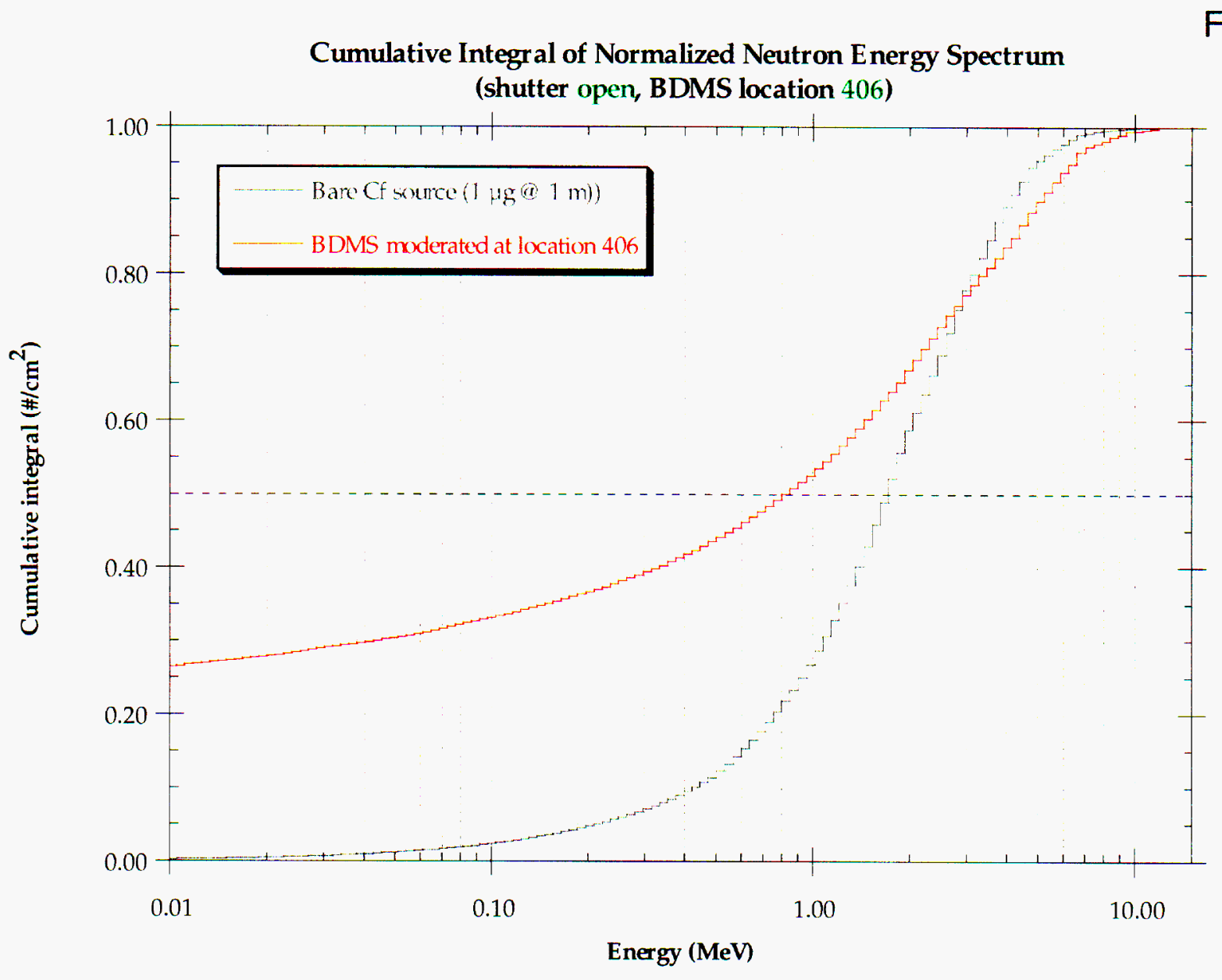


Figure 22

\section{Cumulative Integral of Normalized Neutron Energy Spectrum} (shutter closed, BDMS location 401)

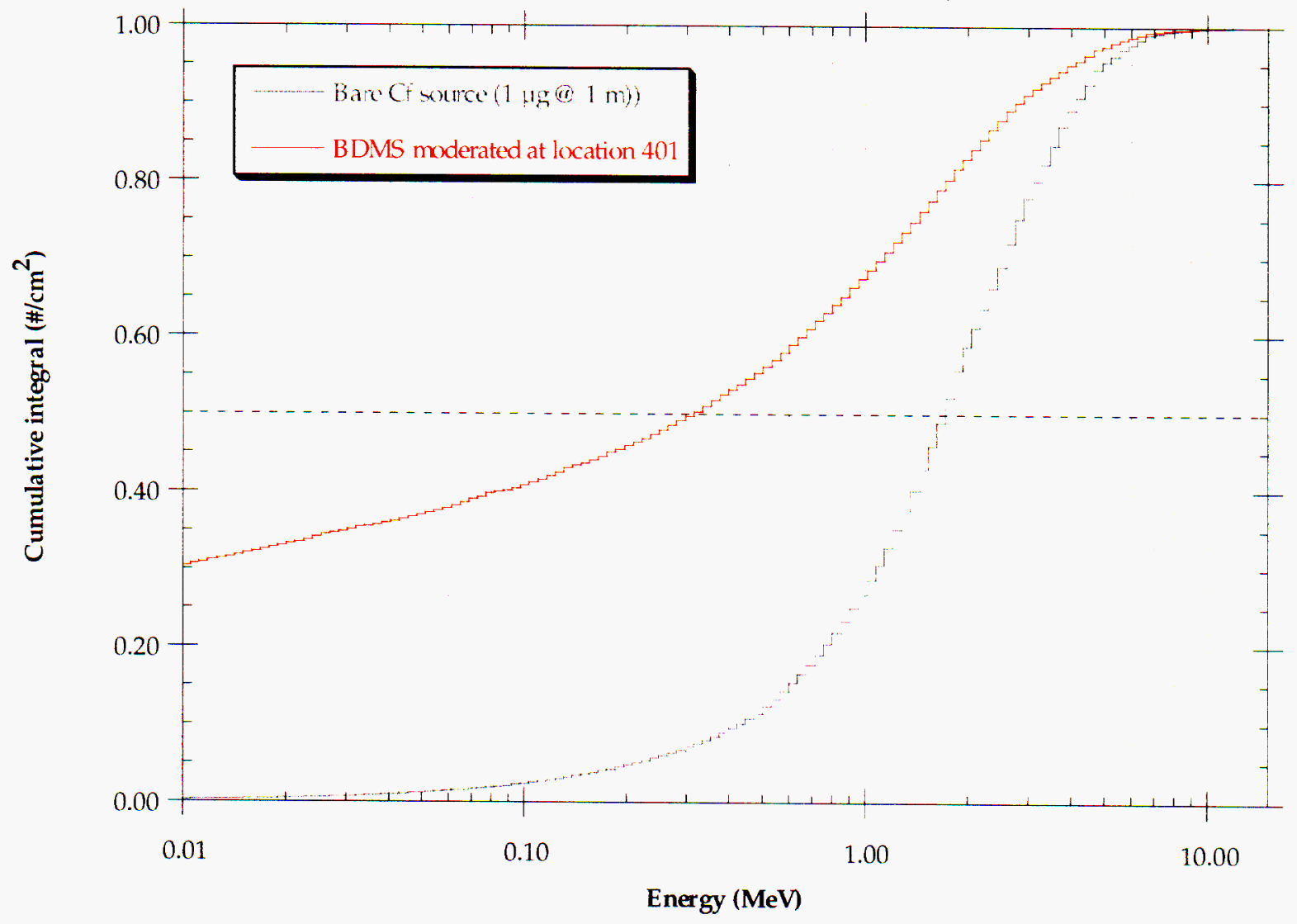


Figure 23

Cumulative Integral of Normalized Neutron Energy Spectrum (shutter closed, BDMS location 402)

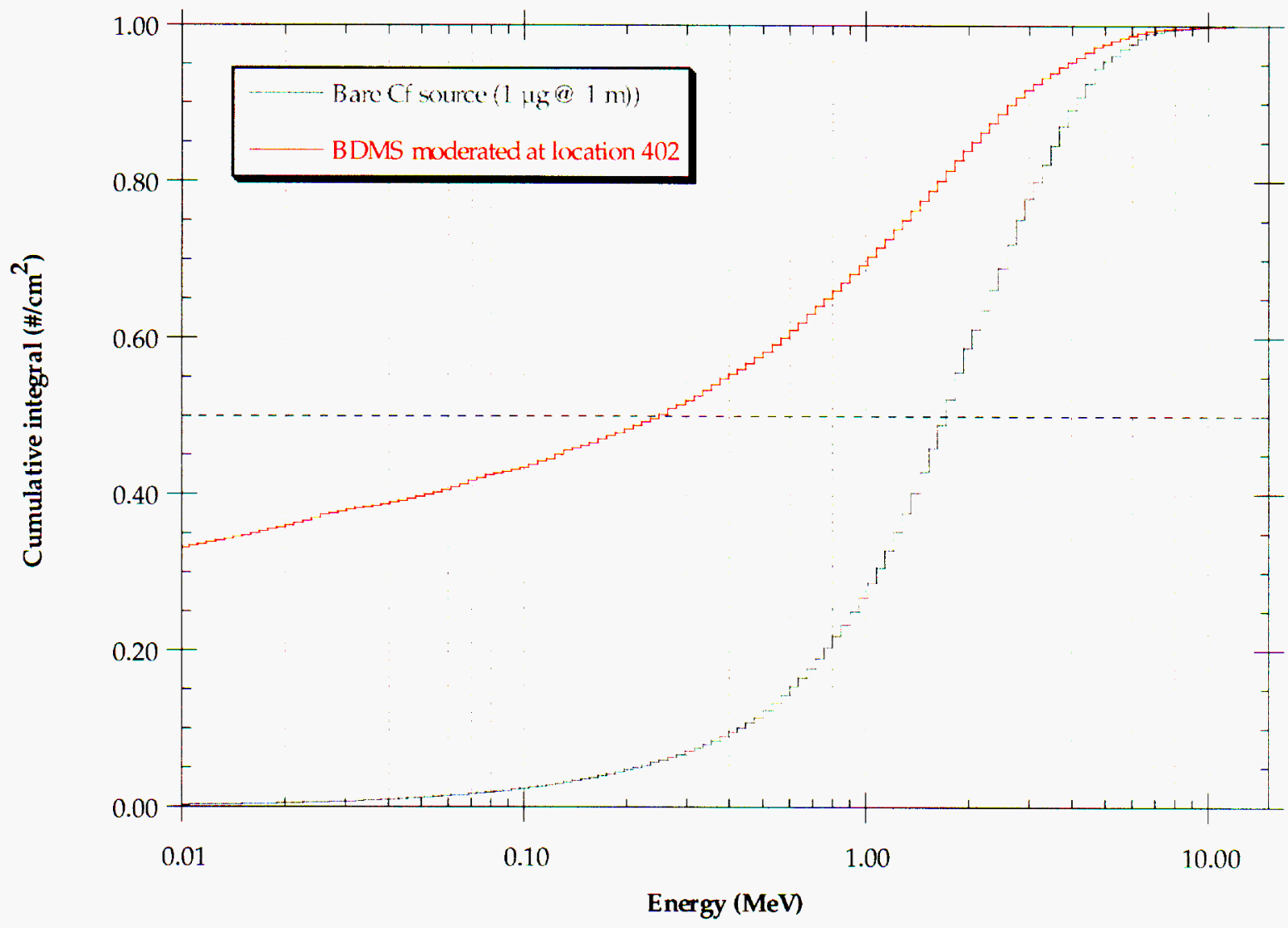


Cumulative Integral of Normalized Neutron Energy Spectrum

Figure 24 (shutter closed, BDMS location 403)

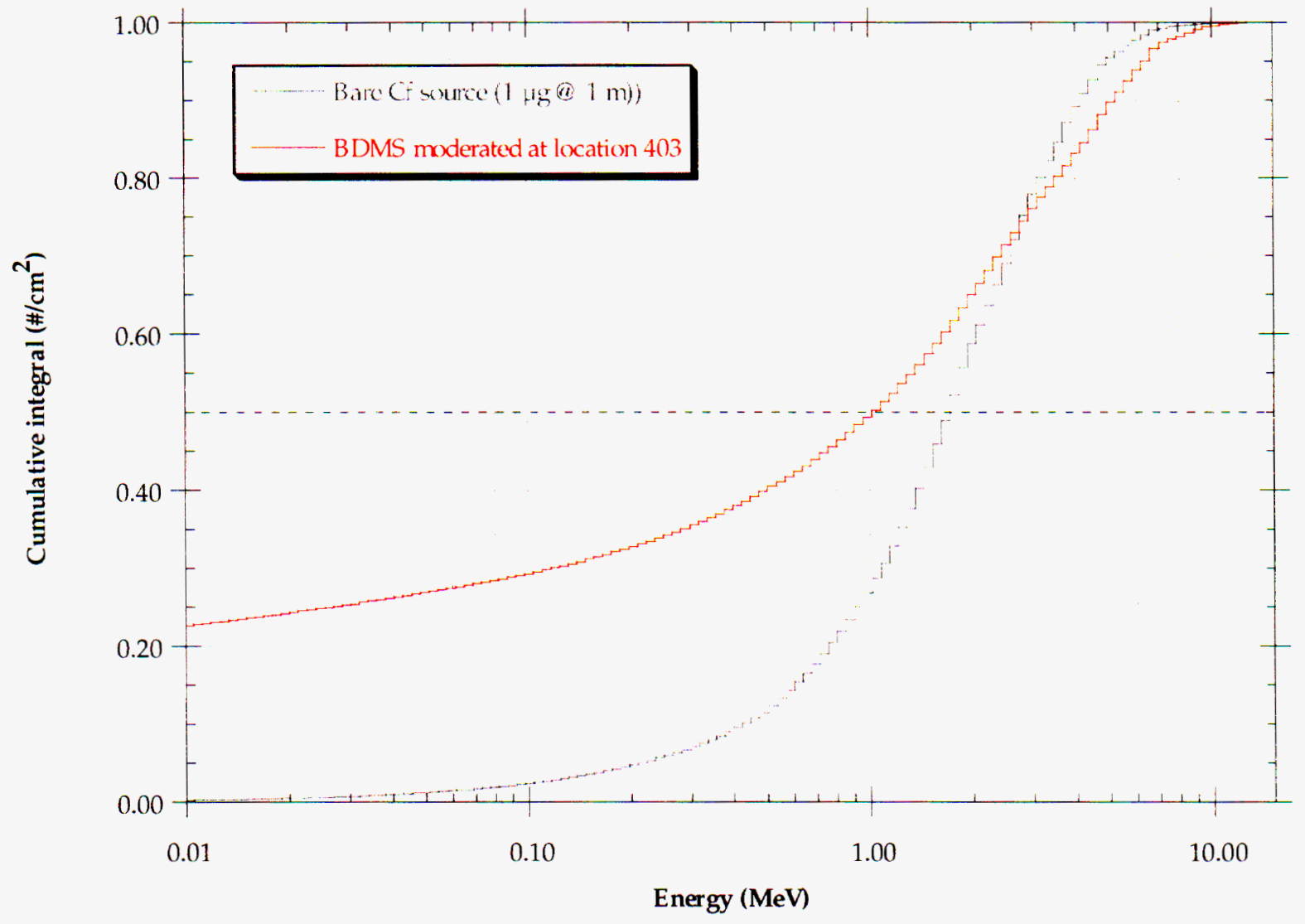


Cumulative Integral of Normalized Neutron Energy Spectrum (shutter closed, BDMS location 404)

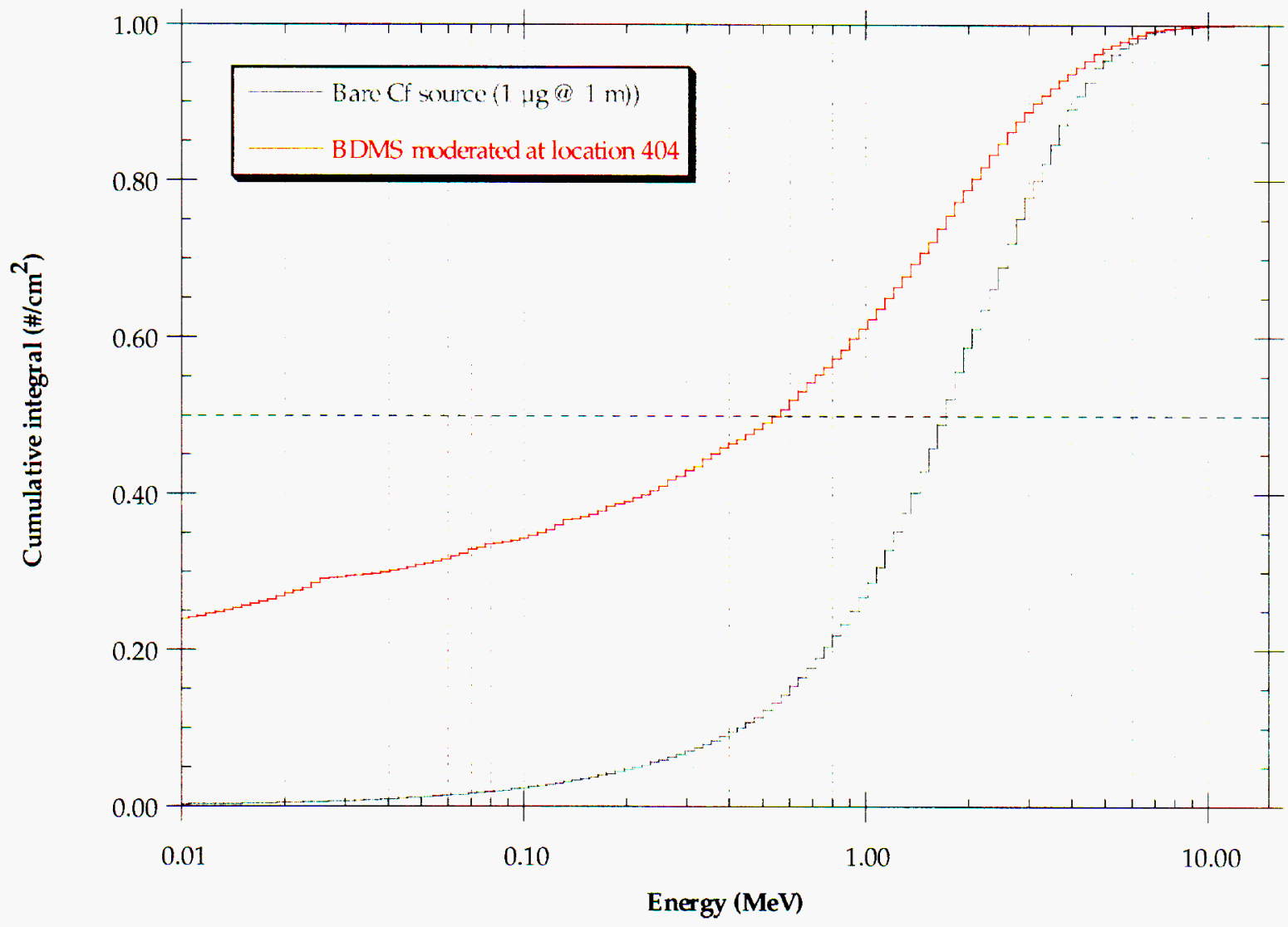




\section{Cumulative Integral of Normalized Neutron Energy Spectrum}

Figure 26 (shutter closed, BDMS location 405)

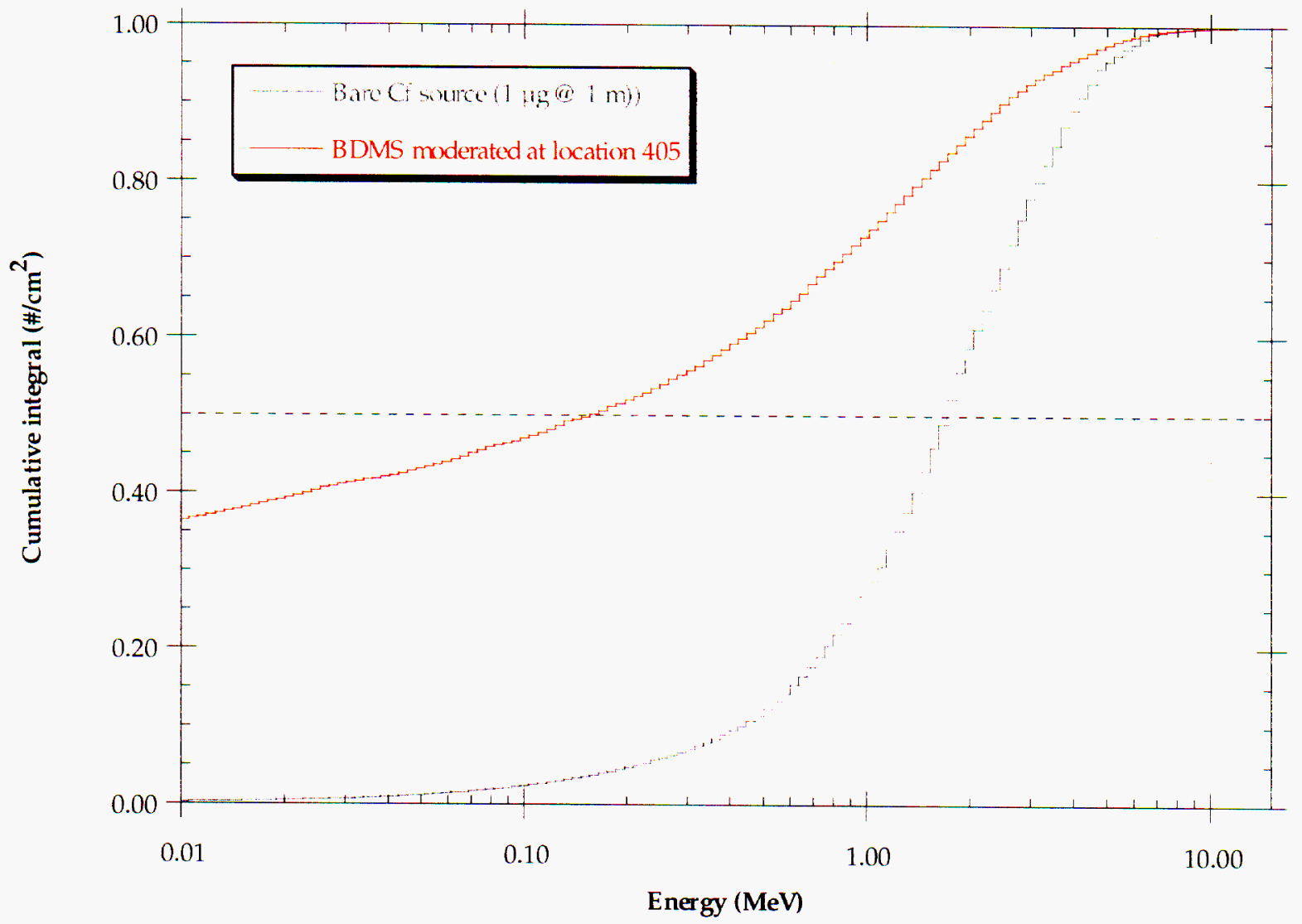


Figure 27

Cumulative Integral of Normalized Neutron Energy Spectrum (shutter closed, BDMS location 406)

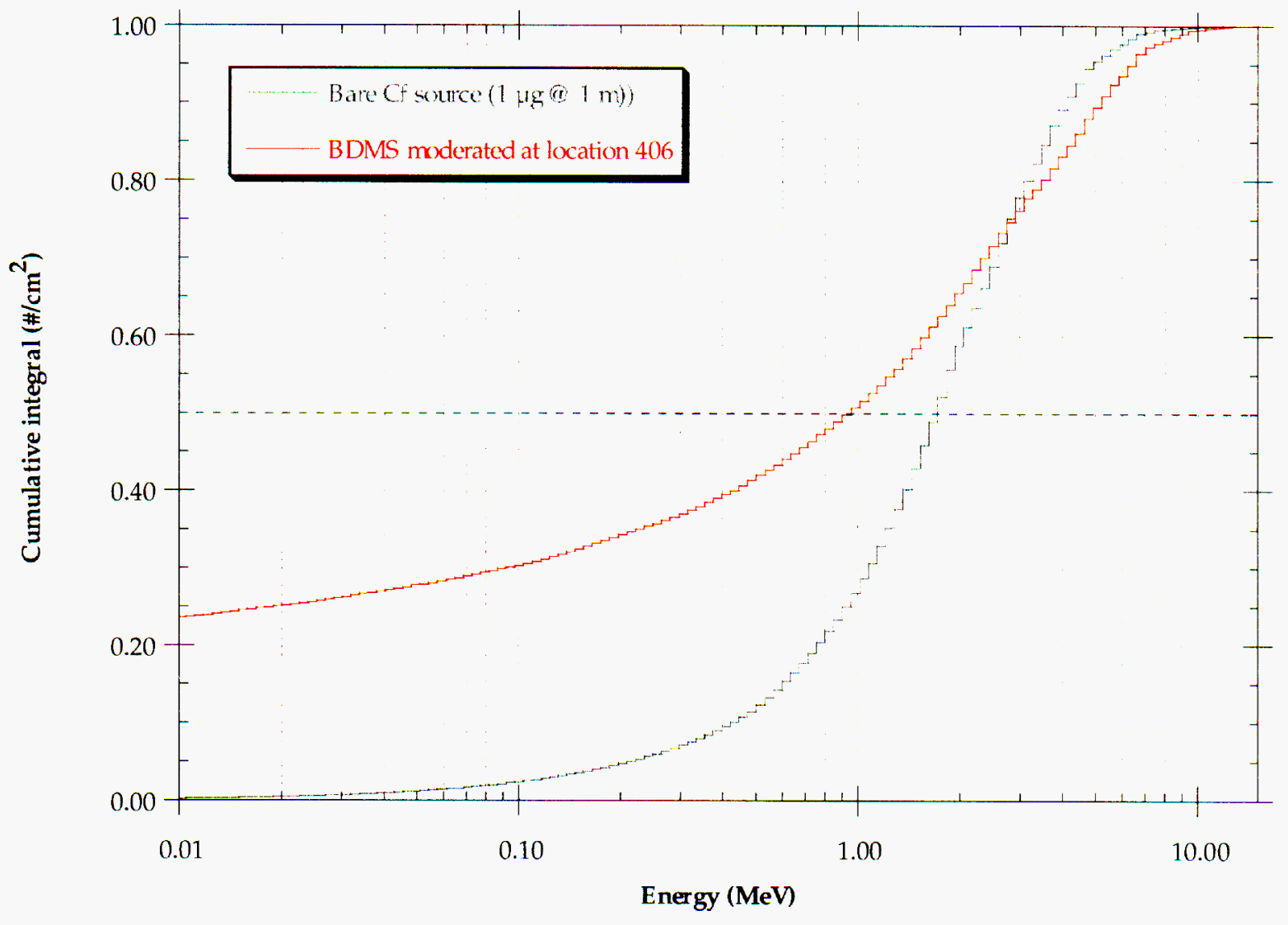

